Research Article

\title{
Spatial Differentiation and Elements Influencing Urban Resilience in the Middle Reaches of the Yangtze River under the COVID-19 Pandemic
}

\author{
Xin Hou $(\mathbb{D}$, Qianli Ma $(\mathbb{D}$, and Xuan Wang $(\mathbb{D}$ \\ School of Architecture, Tianjin University, Tianjin, China \\ Correspondence should be addressed to Xin Hou; workhou@126.com
}

Received 24 December 2020; Revised 5 April 2021; Accepted 8 May 2021; Published 8 June 2021

Academic Editor: Lijun Pei

Copyright ( 2021 Xin Hou et al. This is an open access article distributed under the Creative Commons Attribution License, which permits unrestricted use, distribution, and reproduction in any medium, provided the original work is properly cited.

\begin{abstract}
Since the outbreak of COVID-19 in Wuhan City, Hubei Province, in December 2019, the middle reaches of the Yangtze River became the key areas of the spread of the pandemic and association, and also as the urban economic recovery process after the pandemic eased, it provided an excellent opportunity to research urban resilience. From the viewpoint of urban social-ecological system resilience in public health emergencies, this study comprehensively applies the spatial econometrics, geodetector model, and other methods to investigate the urban resilience level, spatial differentiation, and dominant elements in the middle reaches of the Yangtze River under the impact of the pandemic. This study would aid in providing a scientific basis for sustainable spatial planning and governance. The results demonstrated that the urban resilience in the middle reaches of the Yangtze River had notable spatial agglomeration features, eight elements including tertiary industry proportion possessed a robust explanatory power to the spatial differentiation of urban resilience, and the explanatory power was markedly enhanced after the interaction between influential elements of economic and ecological subsystems. Thus, to upgrade the system cycle mechanism and augment the endogenous power for urban development, we need to focus more on the flow of innovative elements in central cities, the optimization of ecological and safe spatial patterns in Hunan and Hubei Provinces, and the innovation of sustainable supply chain in the entire region.
\end{abstract}

\section{Introduction}

After the first case of the coronavirus disease 2019 (COVID19) was reported in December 2019 in Wuhan City, Hubei Province [1] (hereafter referred to as "pandemic"), the disease spread quickly to other regions, especially the middle reaches of the Yangtze River, which was the most severely affected area being centered on Wuhan City. The operation of socioeconomic orders in each city was seriously affected; the large-scale supply chain was interrupted, reflecting on spatial planning, production, supply modes, and urban governance. The World Health Organization defined the pandemic as a public health emergency of international concern [2]. Currently, the prevention and control of the pandemic have entered into the normalized stage, and the recovery process of urban social economy has provided an opportunity for the research and data collection of urban resilience. With the background of growing uncertain perturbation factors, such as public health emergency represented by the pandemic, enhancing the adaptive circulating ability of city as a social-ecological system (SES) and conducting effective spatial planning and governance are of great significance for urban sustainable development.

The research on the resilience of urban SES after public health emergency and other disaster events has always been a hot topic in public management, economic geography, and urban and rural planning, involving the comprehensive impact of various elements of the SES and primarily focusing on the role of government and market or the valuation of urban social economy recovery. Ma and Ren [3] and Olcott 
and Oliver [4] conducted relevant research and quantitative analyses on the allocation relation and dynamic stability of resource elements in complex systems. Regarding the COVID-19 pandemic, Wang and Zhao [5], Ma et al. [6], and $\mathrm{Li}$ et al. [7] examined the spatial differentiation features of a domestic epidemic from different temporal and spatial scales and revealed the correlation features of such elements as landscape patterns of ecological and construction lands, emergency response management and government regulation, and regional centrality with the pandemic. Besides, Yang et al. [8] proposed a new calculation and application method for economic complex systems that could be used in engineering applications, including population-scale control and economic and market activities. However, considering the data timeliness and accuracy, related studies have primarily explored the spatial correlation and macrocontrol between epidemiological transmission and socioeconomic elements, but the empirical studies on urban resilience in the case of the pandemic and the research into proper governance measures in light of local conditions remain unexplored.

In this study, empirical analysis is performed for the urban resilience in the middle reaches of the Yangtze River under the pandemic based on the existing literature. In addition, this study explores the spatial differentiation and dominant elements of urban resilience using a geodetector model. This study also provides a scientific basis for the ecological and safe spatial pattern planning and governance and the sustainable innovation and development of the supply chain, as well as enhancing the urban resilience and sustainable development capacity.

\section{Literature Review}

Resilience, first originating from Latin word "resilio," implies "returning to the original state" [9], and the concept connotation has experienced development in multidisciplinary context and social transformation and is progressively applied to studies on urban problems. The standpoints of the study evolve in three stages: engineering resilience, ecological resilience, and social-ecological resilience. A recent study defined urban resilience as the ability of the socialecological network of the urban system to sustain or rapidly restore the good operation status in case of imbalance [10]. Under the theoretical framework of SES adaptive governance, it is essential to coordinate the interrelationship between environment, economy, and society to ascertain the resilience management strategy and regulate the state of the complex adaptive system, thereby augmenting the urban resilience and further coping with nonlinear change [11].

Regarding dynamic adaptive governance, Ma implemented a series of analytical and applied studies on management, economy, and dynamics systems based on the system theory [3, 12-16]. In particular, researching the complexity of the closed-loop supply chain system for resource renewability is conducive to elucidating the supplydemand correlation between government and market in the context of urban resilience and sustainable development $[17,18]$. Regarding the construction of an urban resilience evaluation model and the selection of indicators, the Resilience Alliance proposed the strategic management target and research framework for urban resilience under the SES. Fox-Lent et al. [19] established the Resilience Matrix Framework for four stages of coping with perturbation factors (prepare, absorb, recover, and adapt) from the physical, information, cognitive, and social perspectives. Orencio et al. built the Localized Disaster-Resilience Index that focused on environmental and natural resource management, financial instruments, social protection, technical measures, and planning systems [20].

The modeling method for urban resilience measurement has different focuses owing to specific research objectives and objects, and there is lack of a set of authentic measurement index systems for index selection. Nevertheless, as the system resilience is affected by multiple elements and changes dynamically, the research on specific events in a specified region should be progressive and dynamic, and the guiding function of the research conclusion on spatial coordinated development and adaptive governance should be emphasized. This pandemic could serve as an efficient empirical test for related studies on urban resilience assessment, which is advantageous to further explore and comprehend the influential elements and interrelation of urban resilience, thus optimizing the supply and demand from the source and actively increasing the resilience of urban SES.

\section{Model Construction}

3.1. Research Areas. Wang and Zhao [5] illustrated that the distribution of the number of COVID-19 infections and infection growth rate exhibited notable spatial agglomeration features in the entire country, which is in line with the range of urban agglomerations in the middle reaches of the Yangtze River and the three major coastal city agglomerations, and the aggregation is slowly weakened from the urban agglomerations in the middle reaches of the Yangtze River to other urban agglomerations. Thus, we selected 28 cities in the middle reaches of the Yangtze River, which were markedly affected by the perturbation factors of the pandemic, as the research areas. Considering the consistency of the research units in terms of the administrative and geographical-economic elements, as well as the data statistics, we excluded three counties directly under the provincial government, namely, Xiantao City, Qianjiang City, and Tianmen City, from the scope of this study.

Based on the Development Plan of the Urban Agglomeration in the Middle Reaches of the Yangtze River approved by the State Council in 2015, the urban agglomeration in the middle reaches of the Yangtze River implies the national megaurban agglomeration, with Wuhan City as the center and Wuhan metropolitan area, Changsha-ZhuzhouXiangtan agglomeration, and urban agglomeration around the Poyang Lake as the host components. In 2017, the economic aggregate, population, and area of the urban agglomeration accounted for $9.6 \%, 11.1 \%$, and $3.3 \%$ of the corresponding national indicators, respectively. The research scope (Figure 1) covered 10 cities of Hubei Province (Wuhan City, Huangshi City, Ezhou City, Huanggang City, 
Xiaogan City, Xianning City, Xiangyang City, Yichang City, Jingzhou City, and Jingmen City), 8 cities of Hunan Province (Changsha City, Zhuzhou City, Xiangtan City, Yueyang City, Yiyang City, Changde City, Hengyang City, and Loudi City), and 10 cities of Jiangxi Province (Nanchang City, Jiujiang City, Jingdezhen City, Yingtan City, Xinyu City, Yichun City, Pingxiang City, Shangrao City, Fuzhou City, and Ji'an City). The cities of Hubei Province, Hunan Province, and Jiangxi Province mentioned below merely refer to the cities within the research areas.

3.2. Model Assumption. In this study, we adopted three empirical elements of urban resilience level (Table 1) to measure the specific numerical value and spatial differentiation of the urban resilience level. In addition, the three empirical elements (Table 1) and the elements in the index system of urban resilience level (Table 2) were detected and analyzed to identify the dominant driving elements and the interactions between elements.

Martin et al. claimed that the resilience could be better measured on the basis of recovery extent and speed of an area from external disturbance [28]. According to the specific situation of the pandemic and considering the limitation of single index element during characterization and the subjectivity of the weighted index element system, the three empirical elements (the gross domestic product (GDP) year-on-year growth rate $(Y 1)$, the year-on-year growth rate of total electricity consumption (Y2), and the in-city travel intensity recovery index (Y3)) were selected to jointly characterize the resilience level of urban social economy within the research areas. In particular, the GDP year-on-year growth rate is a vital macroeconomic observation index, the total electricity consumption can be considered a barometer of social economy operation, and the in-city travel intensity often acts as a crucial measurement index for the socioeconomic activity in the field of urban big data analysis. Considering the differences in characterization features and statistical caliber of different empirical elements, the three indexes were defined on the basis of varying time ranges (detailed in Table 1 and Section 3.3).

The index system for elements influencing the urban resilience level was constructed in combination with the connotation of SES resilience. Based on the measurement model of urban SES resilience level of Cutter et al. [21], together with the attention of the public health to issues like the health system, public organization, culture contact, and vulnerable groups [24], we proposed a hypothesis about the index system for influential elements of the urban resilience level regarding the problems exposed in the pandemic (Table 2). The system comprised 4 subsystems, 10 indexes, and 20 elements, involving the resistance ability, adaptive ability, and learning ability that should be possessed by the SES. The four subsystems were social resilience, economic resilience, environmental resilience, and engineering resilience, which interacted with each other and were connected internally and externally, thereby jointly and dynamically adjusting the system status.
3.3. Data Sources. Based on the epidemiological analyses on the prevalent features and trends of the pandemic within the research areas $[29,30]$, the pandemic in the research areas can be categorized into four main stages, namely, outbreak period (from January 10 to February 3), peak period (from February 4 to February 20), plateau period (from February 21 to March 8), and involuting period (from March 9 to April 26). On February 21, 2020, the Central Committee held a Political Bureau meeting to deploy the work for pandemic prevention and control, as well as socioeconomic development, so that the pandemic prevention and control could fully enter the second stage. Hence, February 21 was set as a crucial time point in this study. In consideration of the pandemic analysis in the research areas and different characterization features and calculation methods of the three empirical elements, the selection and calculation for different time ranges were accomplished. Table 3 provides a detailed explanation of the major data source.

It is worth noting that the data of the in-city travel intensity (Y3) were obtained from the Baidu Migration Big Data Platform, which maps the trajectory of population flow through mobile phone location information and is characterized by daily continuity and immediacy. In this study, the data of 2019 and 2020 were crawled and cleaned. However, only the data from January 1 to March 15, 2019, were disclosed, and the mean of the numerical values of 2 consecutive weeks (from March 2 to March 15) was used as the comparative data of the in-city travel intensity in 2019 to exclude the impact of the passenger transport during Spring Festival. In 2020, considering that the pandemic entered a plateau period and a new stage of prevention and control since February 21, with February 24 (Monday) being the start point and special values of the May Day holiday being eliminated, the data for a total of 9 weeks from February 24 to April 26 were obtained after crawling and processing of daily data.

\subsection{Main Research Methods}

3.4.1. Spatial Differentiation Analysis Method: Spatial Autocorrelation. Spatial autocorrelation reflects the correlativity of a certain geographic phenomenon or attribute value in an area unit with that in adjacent area units [31]. In this study, we used the Global Moran's I and Local Indicators of Spatial Association (LISA) index to measure the degrees of global autocorrelation and local autocorrelation of urban resilience, respectively, as per the following formula:

$$
\text { Moran's } I=\frac{n \sum_{i=1}^{n} \sum_{j=1}^{n} W_{i j}\left(x_{i}-\bar{x}\right)\left(x_{j}-\bar{x}\right)}{\sum_{i=1}^{n} \sum_{j=1}^{n} W_{i j} \sum_{i=1}^{n}\left(x_{i}-\bar{x}\right)^{2}},
$$

where $n$ denotes the total number of urban units; $x_{i}$ and $x_{j}$ indicate the observed values of variable $x$ in city $i$ and city $j$, respectively; $\bar{x}$ denotes the mean of the observed values; and $W_{i j}$ implies the spatial weight matrix value. The range of values is $[-1,1]$; the numerical value tending to 1 suggests that the distribution of similar units is more concentrated, that is, spatial agglomeration; the value tending to -1 
suggests the high degree of spatial dispersion; and the value close to 0 indicates that the degree of global autocorrelation is low.

$$
\operatorname{LISA}_{i}=x_{i}^{\prime} \sum_{j=1}^{n} W_{i j} X_{j}^{\prime}
$$

where $x_{i}^{\prime}$ and $x_{j}^{\prime}$ signify standardized values of variable $x^{\prime}$ in city $i$ and city $j$, respectively, and $W_{i j}$ denotes the spatial weight matrix value. Local autocorrelation can be categorized into five types of agglomeration: $\mathrm{HH}$ type, LL type, HL type, LH type, and "not significant" type. Of these, HH type and LL type are positive correlation, suggesting a high degree of spatial aggregation; HL type and LH type are negative correlation, suggesting a high degree of spatial dispersion; and "not significant" implies no obvious agglomeration and dispersion characteristics.

3.4.2. Dominant Element Analysis Method: Geodetector. Geodetector is a set of statistical methods to detect spatial differentiation and related driving elements [32]. We used differentiation and factor detection in modeling tools and interaction detection to identify the dominant driving elements and the interactions between elements. In the differentiation and factor detection, $q$ value was applied to measure the explanatory power of element $X$ to the spatial differentiation of the urban resilience attribute $\mathrm{Y}$, with a range $[0,1]$; the larger the value was, the stronger the explanatory power to the spatial differentiation was. It was calculated as follows:

$$
q=1-\frac{\sum_{h=1}^{L} N_{h} \sigma_{h}^{2}}{N \sigma^{2}}
$$

where $N$ indicates the total number of urban units and $\sigma^{2}$ is the variance of $Y$ value. In the interaction detection, there were five types of interactions: nonlinear diminution $(q(X 1 \cap X 2)<\min (q(X 1), q(X 2)))$; single-factor nonlinear diminution $(\min (q(X 1), \quad q(X 2))<q(X 1 \cap X 2)<\max (q(X 1)$, $q(X 2)))$; two-factor enhancement $(q(X 1 \cap X 2)>\max (q(X 1)$, $q(X 2)))$ independent enhancement $(q(X 1 \cap X 2)=$ $q(X 1)+q(X 2))$; and nonlinear enhancement $(q(X 1 \cap X 2)$ $>q(X 1)+q(X 2))$.

3.4.3. Urban Spatial Pattern Analysis Method: Landscape Metrics. According to the land-cover data, we divided landscape types into cultivated land, ecological land, construction land, and unoccupied land. Among them, we specifically measured and calculated the ecological land and construction land using FRAGSTATS software platform and selected six indexes (Table 4) to characterize the urban spatial patterns in the middle reaches of the Yangtze River.

The formulas for the abovementioned landscape metrics are as follows:

$$
\mathrm{PD}_{i}=\frac{n_{i}}{A} \times 10000 \times 100
$$

where $n_{i}$ denotes the total area of landscape element $i$ and $A$ denotes the total area of all landscape types, namely, the number of patches per unit area (number of patches/100 hectares).

$$
\mathrm{AI}_{i}=\left[\frac{g_{i i}}{\max \longrightarrow g_{i i}}\right] \times 100
$$

The AI equals the ratio of the number of self-adjacent public edges to the most probable number of public edges of the landscape element network. In formula (5), $g_{i i}$ signifies the number of similar adjacent patches of the landscape type, which is calculated according to the length of the common boundary between pixels of the same type of patches. The AI is the highest when the length of the common boundary of all pixels of a specific type of patches reaches the maximum value; otherwise, it is the lowest.

$$
\mathrm{IJI}_{i}=\frac{-\sum_{k-1}^{m}\left[\left(e_{i k} / \sum_{k=1}^{m} e_{i k}\right) \ln \left(e_{i k} / \sum_{k=1}^{m} e_{i k}\right)\right]}{\ln (m-1)},
$$

where $m$ denotes the total number of patch types in the landscape; $e_{i k}$ means the edge length of patch $i$ adjacent to the patch of landscape element $k$; and the numerical value equal to 100 illustrates that the edge length of neighboring patches is equal, that is, the probability of vicinity between patches is equal.

$$
\operatorname{COHESION~}_{i}=\left[1-\frac{\sum_{i=1}^{m} \sum_{j=1}^{n} P_{i j}^{*}}{\sum_{i=1}^{m} \sum_{j=1}^{n} P_{i j}^{*} \sqrt{a_{i j}^{*}}}\right] \times\left[1-\frac{1}{\sqrt{Z}}\right]^{-1} \times 100,
$$

where $P_{i j}^{*}$ represents the perimeter of the patch (cell count); $a_{i j}^{*}$ denotes the patch area (cell count); and $Z$ implies the number of cells in the landscape.

$$
\operatorname{CONTAG}_{i}=\left[1+\frac{\sum_{i=1}^{m} \sum_{k=1}^{m}\left[\left(P_{i}\right)\left(g_{i k} / \sum_{k=1}^{m} g_{i k}\right)\right] \ln \left[\left(P_{i}\right)\left(g_{i k} / \sum_{k=1}^{m} g_{i k}\right)\right]}{2 \ln (m)}\right] \times 100
$$

where $m$ denotes the total number of patch types in the landscape; $P_{i}$ implies the percentage of area of patch type $i$; and $g_{i k}$ implies the number of adjacent patch type $i$ and patch type $k$.

$$
\mathrm{SHDI}_{i}=-\sum_{i=1}^{m}\left(p_{i} \ln p_{i}\right)
$$

where $p_{i}$ signifies the proportion of patch type $i$ in the landscape. 


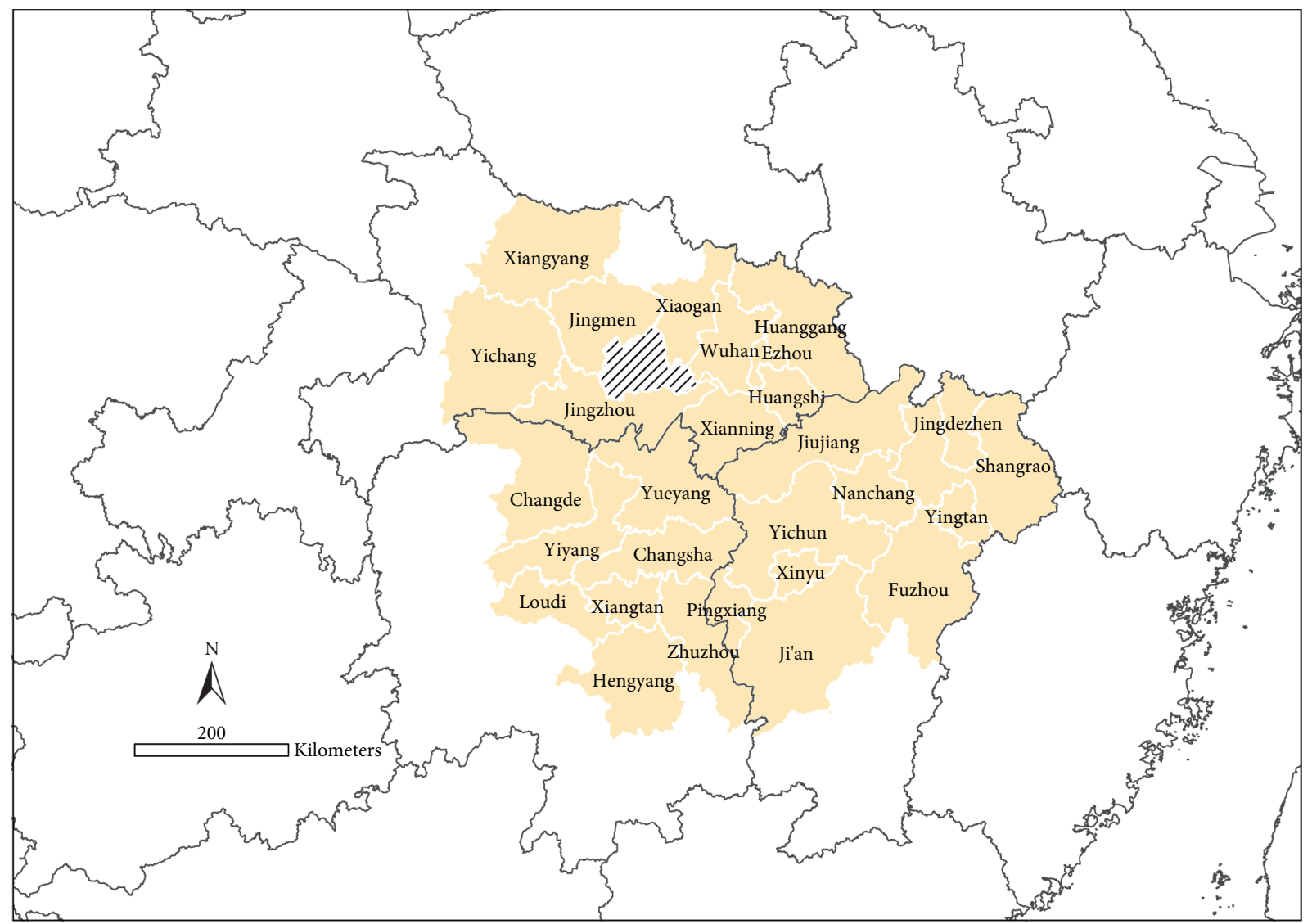

Figure 1: Research areas.

\section{Empirical Analysis}

\subsection{Measurement and Spatial Differentiation of the Urban} Resilience Level in the Middle Reaches of the Yangtze River under the Pandemic

4.1.1. Measurement of Resilience Level of Cities. We obtained the GDP year-on-year growth rate $(Y 1)$, year-on-year growth rate of total electricity consumption (Y2), and in-city travel intensity recovery index (Y3) of cities in the research areas through the measurement and then separately subjected them to statistical Pearson correlation test with the pandemic disaster severity $(Y 0)$. The results demonstrated that the $Y 2$ and $Y 3$ were significantly correlated with $Y 0$ (Table 5).

Figure 2 displays the spatial distribution trend of the urban resilience level. For the urban resilience level measured per the GDP year-on-year growth rate, Jingdezhen City (7.8\%), Changsha City (3.1\%), Shangrao City (3.1\%), and Hengyang City (3.0\%) were the top four cities with a high level. The cities of Hunan Province revealed a more advantageous and balanced state. Regarding the year-onyear growth rate of total electricity consumption, the top three were 25.1\% (Ji'an City), 21.6\% (Yichun City), and $19.4 \%$ (Fuzhou City); the cities of Hunan Province displayed an uneven recovery trend, with the values decreasing from south to north; and the cities of Jiangxi Province and Zhuzhou City and Hengyang City in Hunan Province displayed outstanding performance. The cities in Hubei Province exhibited negative values in the above two indicators. Regarding the travel intensity recovery index in cities, six cities, including Ji'an, were in the first echelon. Notably, Huanggang City (97.73\%) and Jingzhou City (93.42\%) in Hubei Province demonstrated good recovery levels in this indicator.

\subsubsection{Study on Spatial Differentiation of the Urban Resilience} Level. According to Table 6, the urban resilience level represented by three elements revealed a significant spatial aggregation effect, which was stronger than the pandemic disaster severity. We conducted LISA clustering to further interpret local autocorrelation (Figure 3). Precisely, when the urban resilience level was represented by the GDP yearon-year growth rate, a Low-Low Cluster (low-efficiency type) was formed in the northern wing of the urban agglomeration in the middle reaches of the Yangtze River, which comprised Wuhan City, Ezhou City, Huangshi City, Huanggang City, Xiaogan City, Jingmen City, and Xiangyang City, suggesting that the resilience of these areas and surrounding areas was at a low value. A High-High Cluster (high-efficiency type) of urban resilience was formed in the 
TABLe 1: Empirical elements of the urban resilience level.

\begin{tabular}{|c|c|c|}
\hline Empirical element & Abbreviation & Formula \\
\hline$Y 1:$ GDP year-on-year growth rate & GDP & $\begin{array}{c}F(j)_{g d p}=\left(G_{j 1}-G_{j 2}\right) / G_{j 2} \text {, where } G_{j 1} \text { denotes the constant-price GDP of city } j \text { in } \\
\text { the first three quarters of } 2020 \text { and } G_{j 2} \text { denotes the constant-price GDP of city } j \text { in } \\
\text { the first three quarters of } 2019 \text {. }\end{array}$ \\
\hline $\begin{array}{l}\text { Y2: year-on-year growth rate of total } \\
\text { electricity consumption }\end{array}$ & $\mathrm{Tec}$ & $\begin{array}{l}F(j)_{t e c}=\left(E_{j 1}-E_{j 2}\right) / E_{j 2} \text {, where } E_{j 1} \text { denotes the total electricity consumption with } \\
\text { constant energy consumption of city } j \text { in July } 2020 \text { and } E_{j 2} \text { denotes the total } \\
\text { electricity consumption with constant energy consumption of city } j \text { in July } 2019 \text {. }\end{array}$ \\
\hline $\begin{array}{l}\text { Y3: in-city travel intensity recovery } \\
\text { index }\end{array}$ & $\mathrm{Td}$ & $\begin{array}{l}F(j)_{t d}=T_{j 1} / T_{j 2} \text {, where } T_{j} \text { means the in-city travel intensity of city } j \text {, namely, the } \\
\text { indexation result of the ratio of the number of travelers to the resident population in } \\
\text { the city; } T_{j 1} \text { denotes the daily data of the in-city travel intensity of city } j \text { from } \\
\text { February } 24 \text { to April } 26,2020 \text { (a total of } 9 \text { weeks); and } \overline{T_{j 2}} \text { denotes the mean of the } \\
\text { daily data of the in-city travel intensity from March } 2 \text { to } 15,2019 \text {. }\end{array}$ \\
\hline Y0: pandemic disaster severity & Ds & $\begin{array}{c}F(j)_{d s}=\sum_{t} \text { pop }_{t} \text {, where } p o p_{t} \text { denotes the total number of confirmed cases in city } j \\
\text { as of February } 21,2020 .\end{array}$ \\
\hline
\end{tabular}

TABLE 2: Index system for influential elements of the urban resilience level [21-27].

\begin{tabular}{|c|c|c|c|}
\hline Subsystem & Index & Element & $\begin{array}{l}\text { Element } \\
\text { attribute }\end{array}$ \\
\hline \multirow{5}{*}{ Social resilience } & \multirow[t]{2}{*}{ Social pressure } & $\begin{array}{l}\text { S1: per-capita disposable income of urban residents } \\
\text { S2: registered unemployment rate in urban areas }\end{array}$ & + \\
\hline & & S3: number of beds per 10,000 people & + \\
\hline & Medical security & $\begin{array}{l}\text { S4: number of practicing (assistant) doctors per } 10,000 \\
\text { people }\end{array}$ & + \\
\hline & \multirow{2}{*}{$\begin{array}{l}\text { Cultural education } \\
\text { Social governance }\end{array}$} & S5: number of university students per 10,000 people & + \\
\hline & & S6: expenditures in the local general public budget & + \\
\hline \multirow{4}{*}{ Economic resilience } & \multirow{2}{*}{ Industrial scale } & E1: GDP per land area & + \\
\hline & & E2: GDP growth rate & + \\
\hline & \multirow{2}{*}{$\begin{array}{c}\text { Industrial structure } \\
\text { Scientific and technological } \\
\text { innovation }\end{array}$} & E3: proportion of tertiary industry & + \\
\hline & & E4: number of authorized invention patents & + \\
\hline \multirow{6}{*}{$\begin{array}{l}\text { Environmental } \\
\text { resilience }\end{array}$} & \multirow{3}{*}{ Built environment } & N1: proportion of urban construction land & - \\
\hline & & N2: green coverage rate in built-up areas & + \\
\hline & & N3: population density & - \\
\hline & Natural ecology & N4: normalized difference vegetation index (NDVI) & + \\
\hline & \multirow{2}{*}{ Pollution control } & N5: air quality index (AQI) & - \\
\hline & & N6: centralized treatment rate in sewage treatment plants & + \\
\hline \multirow{4}{*}{ Engineering resilience } & \multirow{2}{*}{ Traffic evacuation } & $P 1:$ per-capita road surface & + \\
\hline & & P2: number of buses per 10,000 people & + \\
\hline & Information popularization & P3: proportion of Internet users & + \\
\hline & Shelter & P4: number of schools per 10,000 people & + \\
\hline
\end{tabular}

southeast corner when the urban resilience level was represented by the year-on-year growth rate of total electricity consumption, which comprised Zhuzhou City, Fuzhou City, Yichun City, Ji'an City, and Pingxiang City, and a highresilience cluster area was developed by these areas and the surrounding areas. A Low-Low Cluster was formed in Wuhan City and its surrounding areas. When the urban resilience level was represnted by the in-city travel intensity recovery index, a Low-Low Cluster of urban resilience was formed, comprising Wuhan City, Ezhou City, and Huangshi City.

Hence, the resilience level of cities around Wuhan City and in the north of the middle reaches of the Yangtze River was relatively low. For the urban resilience with the total electricity consumption as a single indicator, the cities in the south of the middle reaches of the Yangtze River exhibited a better recovery trend. Regarding the situation in each province, the resilience of Xinyu City was relatively low in Jiangxi Province.

We concretely analyzed the in-city travel intensity recovery index by time periods (Table 7 , Figure 4); its spatial relationship underwent the process of "significant aggregation," "random, "short-term discretization," and "long-term random." It had been roughly in the dynamic change of lowvalue cluster in the surrounding areas of Wuhan City and high-value cluster in the southeast corner since the beginning of the study, and there existed a short-term situation of a high-value cluster in some cities of Hubei Province. Considering the particularity of time nodes, we believe that it had a specific relationship with the local policies on pandemic prevention and control. As of April 26, the travel intensity in all cities (except Wuhan) was basically the same 
TABLE 3: Data sources.

\begin{tabular}{|c|c|c|}
\hline Type & Data name & Data source \\
\hline $\begin{array}{l}\text { Disclosure of } \\
\text { government affairs }\end{array}$ & $\begin{array}{c}18 \text { indexes of influential elements of urban } \\
\text { resilience, including per-capita disposable income of } \\
\text { urban residents }\end{array}$ & $\begin{array}{l}\text { Statistical website of each city and province, statistical } \\
\text { yearbook of each city and province }(2018) \text {, and China City } \\
\text { Statistical Yearbook }(2017,2018) \\
\text { Monthly statistical report of statistics bureau of each city and } \\
\text { province. City and provincial governments, statistics bureaus, } \\
\text { or reform and development commissions through open } \\
\text { application processes obtaining missing numerical values }\end{array}$ \\
\hline Inte & n-city tray & Baidu Migration Big Data Platform (http://qianxi.baidu.com/) \\
\hline \multirow{4}{*}{$\begin{array}{l}\text { Public network } \\
\text { dataset }\end{array}$} & $\begin{array}{l}\text { Spatial distribution dataset of NDVI in China in } \\
\qquad 2017\end{array}$ & $\begin{array}{l}\text { Resource and Environment Science and Data Center, Chinese } \\
\text { Academy Of Sciences (http://www.resdc.cn/DOI), 2018. DOI: } \\
\qquad 10.12078 / 2018060601 \\
\text { China National Environmental Monitoring Center (http:// }\end{array}$ \\
\hline & $\begin{array}{l}\text { Innovation and entrepreneurship index in urban } \\
\text { China }\end{array}$ & $\begin{array}{l}\text { Center for Enterprise Research (https://www.cer.pku.edu.cn/ } \\
\text { datacenter/lrlxcxcyzs2018gksj/index.htm) }\end{array}$ \\
\hline & $\begin{array}{c}\text { Total number of confirmed cases } \\
\text { Global land-cover remote sensing monitoring } \\
\text { datasets in } 2020\end{array}$ & $\begin{array}{c}\text { https://github.com/HuiyunLiu99/DXY-COVID-19-data } \\
\text { Ministry of Natural Resources of the People's Republic of } \\
\text { China (http://www.globallandcover.com/defaults.html? } \\
\text { type=data\&src=/Scripts/map/defaults/browse. } \\
\text { html\&head=browse) }\end{array}$ \\
\hline & Boundary of administrative vector (De & $\begin{array}{l}1: 1,000,000 \text { National Fundamental Geographic Information } \\
\text { System Database in China (http://www.ngcc.cn/ngcc/) }\end{array}$ \\
\hline
\end{tabular}

TABLE 4: Interpretation table for landscape metrics.

Landscape metrics

Patch density (PD)

Aggregation index (AI)

Interspersion juxtaposition index (IJI)

Patch cohesion index

(COHESION)

Contagion index (CONTAG)

Shannon's diversity index (SHDI)
Ecological significance

It reflects the degree of landscape fragmentation; a higher numerical value indicates a smaller patch and a higher degree of fragmentation.

It reflects the aggregation degree of the same type of patches; a higher numerical value indicates a greater aggregation degree of similar landscape types.

It reflects the overall interspersion juxtaposition of the same patch; a low numerical value implies that this patch is only adjacent to a few other types of patches.

It reflects the natural connectivity of patches; the higher the numerical value, the better the connectivity of the landscape type.

It reflects the agglomeration degree or extension trend of different landscape types, including the spatial information; a high numerical value implies that good connectivity is formed for a specific dominant landscape type.

It reflects the heterogeneity and complexity of landscape types; a higher numerical value indicates more abundant land use, which tends to be evenly distributed.

Note. Refer to the help file of FRAGSTATS v4.2.1 for details.

Table 5: Results of the Pearson correlation analysis of the pandemic disaster severity and urban resilience.

\begin{tabular}{lcc}
\hline Variable & Pearson correlation coefficient & Sig. (two-tailed) \\
\hline$Y 1$ & -0.304 & 0.116 \\
$Y 2$ & $-0.390^{*}$ & $0.040^{*}$ \\
$Y 3$ & $-0.743^{* *}$ & $\leq 0.001^{* *}$ \\
\hline
\end{tabular}

${ }^{* *}$ Correlation is significant at 0.01 level. ${ }^{*}$ Correlation is significant at 0.05 level.

as that in 2019, and the spatial agglomeration effect of this attribute gradually weakened during the study period.

We used the three empirical elements to measure the urban resilience level. The results revealed that, in the event of the COVID-19 pandemic, urban resilience in the middle reaches of the Yangtze River displayed significant characteristics of spatial agglomeration, with a roughly spatial trend of decreasing from south to north. As of the end of April, the urban travel intensity in all cities (except Wuhan) was the same as in 2019. The cities along the southeast wing had a good recovery trend in the year-on-year growth rate of total electricity consumption and in-city travel intensity recovery index. The overall economic recovery and development of the cities in Hunan Province were relatively 


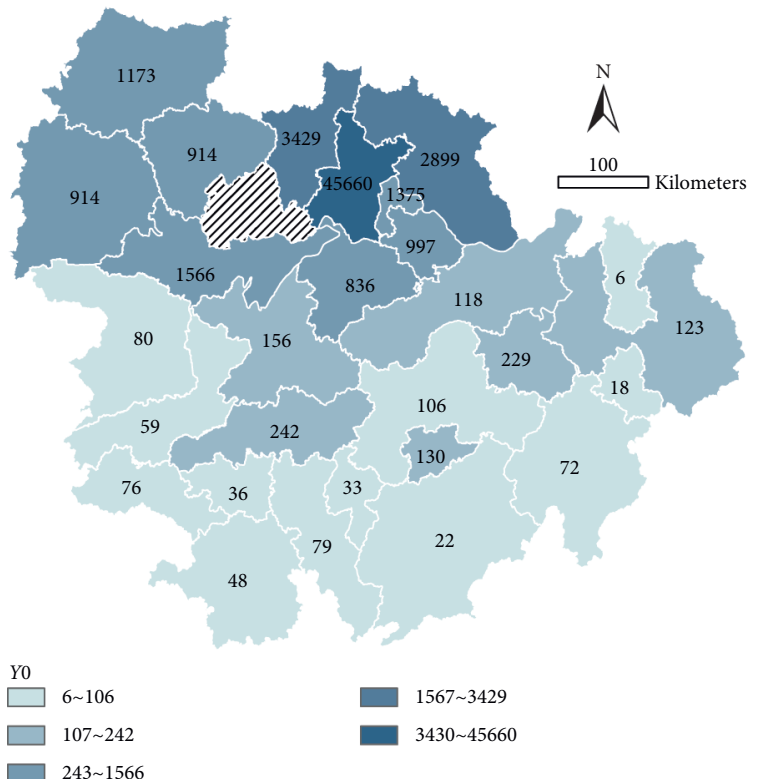

(a)

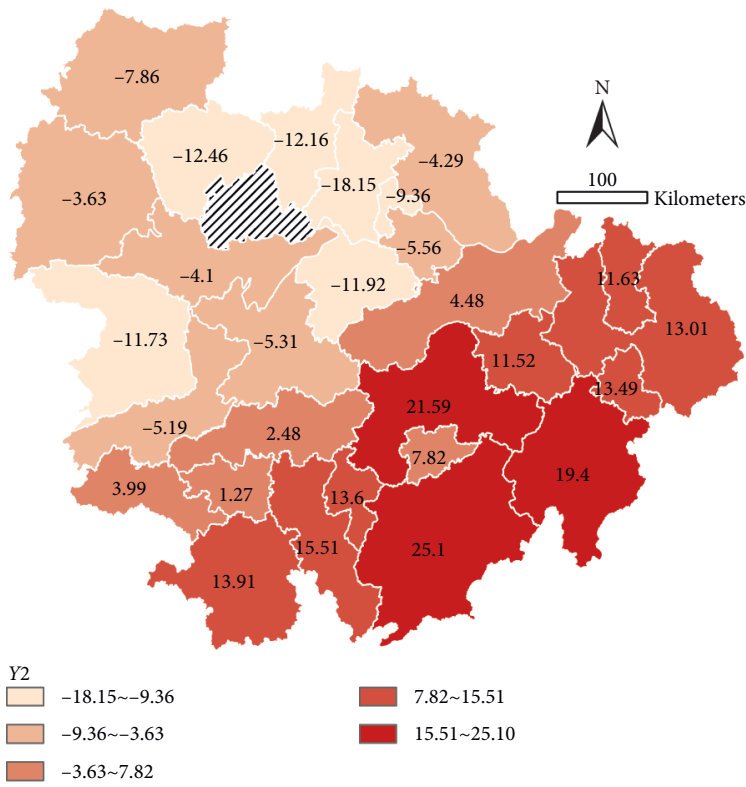

(c)

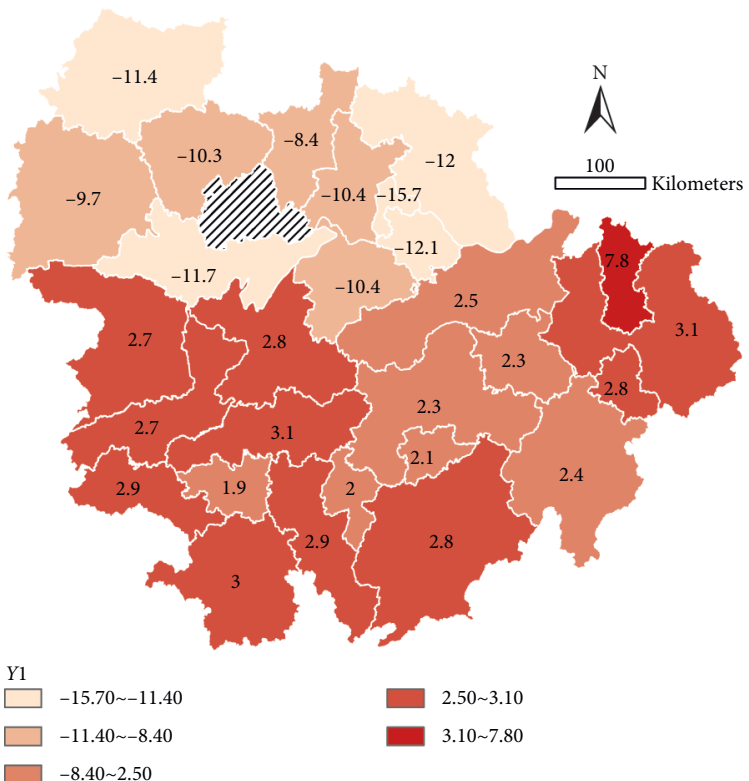

(b)

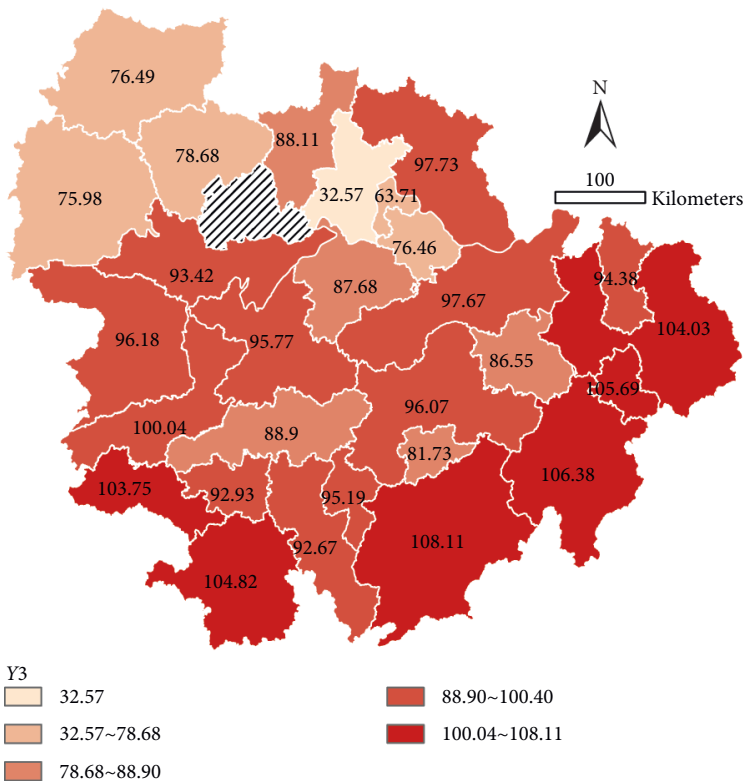

(d)

Figure 2: Pandemic disaster severity and urban resilience level.

balanced, and Xinyu City, Ezhou City, Fuzhou City, Huanggang City, and Jingzhou City had unique presentations meriting focus and further research.

\subsection{Analysis of Elements Influencing the Urban Resilience Level and Spatial Differentiation}

4.2.1. Differentiation and Factor Detection. Table 8 reports the top 10 indicators by the $q$ value. Considering the ranking of the three elements, the proportion of tertiary industry (E3), GDP growth rate (E2), registered unemployment rate in urban areas (S2), AQI (N5), NDVI (N4), green coverage rate in built-up areas (N2), population density (N3), and proportion of Internet users (P3) had a high explanatory power for the spatial differentiation of urban resilience. This indicates that the innovative economic development, stable employment environment, reasonable population size, safe and ecological landscape pattern, and efficient information transmission in the research areas under the disturbance element of the pandemic markedly affect the short-term urban social and economic recovery.

4.2.2. Interaction Detection. According to the interaction detection matrix (Table 9), the driving force of all detection elements after interaction on the urban resilience in the research areas was more significant than the explanatory 
TABLE 6: Results of the global autocorrelation analysis of urban resilience.

\begin{tabular}{lcccc}
\hline Variable & Moran's I & z-score & $P$ value & Description \\
\hline Y1 & $0.663^{* *}$ & $6.05^{* *}$ & $\leq 0.001^{* *}$ & $\leq .001^{* *}$ \\
$Y 2$ & $0.717^{* *}$ & $6.74^{* *}$ & $0.001^{* *}$ & Clustering pattern \\
$Y 3$ & $0.285^{* *}$ & $3.18^{* *}$ & 0.079 & \\
$Y 0$ & 0.020 & 1.76 & & \\
\hline
\end{tabular}

${ }^{* *}$ Correlation is significant at 0.01 level.

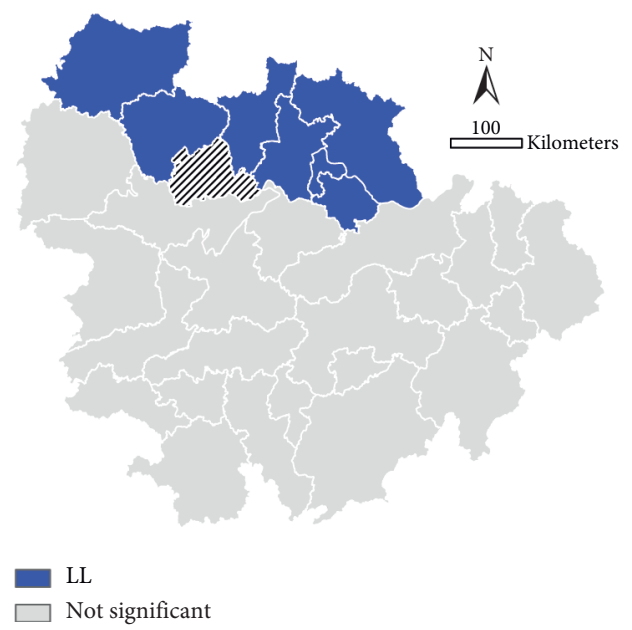

(a)

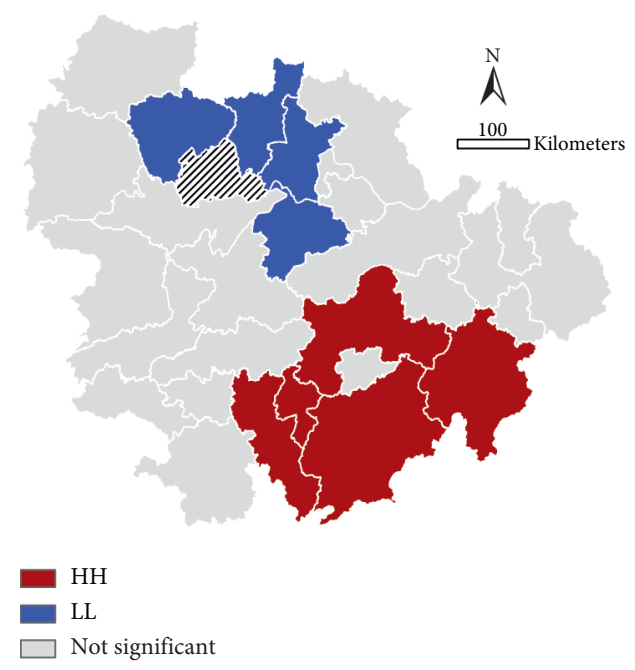

(b)

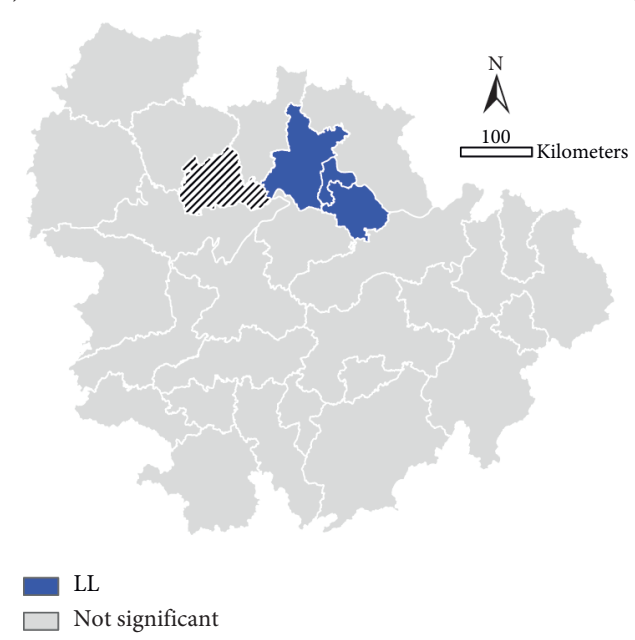

(c)

Figure 3: LISA clustering distribution of urban resilience: (a) Y1; (b) Y2; (c) Y3.

power of a single element. The interaction type of elements included double-element enhancement and nonlinear enhancement, with no independent elements present. Some elements with relatively weak explanatory power in singleelement detection demonstrated strong explanatory power in interaction detection, suggesting that the effect of elements like the number of beds per 10,000 people on the urban resilience in this event could be fully shown when interacting with other elements.

When the urban resilience was characterized by the GDP year-on-year growth rate, the explanatory power of the proportion of the tertiary industry, registered unemployment rate in urban areas, and air quality was markedly enhanced when interacting with other elements. Among them, the air quality $\cap$ proportion of tertiary industry had the strongest explanatory power (0.975). From the standpoint of the year-on-year growth rate of total electricity consumption, the explanatory power of GDP growth rate significantly increased when interacting with other elements. The explanatory power of the proportion of urban construction land, which had a relatively mediocre performance in single-element detection, was as high as 0.793 after 
TABLE 7: Results of the global autocorrelation analysis of the in-city travel intensity.

\begin{tabular}{|c|c|c|c|c|}
\hline Variable & Moran's I & z-score & $P$ & Description \\
\hline Week 1 (2.24-3.1) & $0.569^{* *}$ & $5.24^{* *}$ & $\leq 0.001^{* *}$ & Clustering pattern \\
\hline Week $2(3.2-3.8)$ & $0.615^{* *}$ & $5.66^{* *}$ & $\leq 0.001^{* *}$ & Clustering pattern \\
\hline Week $3(3.9-3.15)$ & $0.486^{* *}$ & $4.66^{* *}$ & $\leq 0.001^{* *}$ & Clustering pattern \\
\hline Week 4 (3.16-3.22) & -0.146 & -1.12 & 0.262 & Not significant \\
\hline Week 5 (3.23-3.29) & $-0.239^{*}$ & $-2.43^{*}$ & $0.015^{*}$ & Discretization pattern \\
\hline Week $6(3.30-4.5)$ & -0.148 & -1.27 & 0.205 & Not significant \\
\hline Week 7 (4.6-4.12) & -0.064 & -0.32 & 0.746 & Not significant \\
\hline Week 8 (4.13-4.19) & 0.062 & 1.23 & 0.218 & Not significant \\
\hline Week $9(4.20-4.26)$ & $0.144^{*}$ & $2.16^{*}$ & $0.031^{*}$ & Clustering pattern \\
\hline
\end{tabular}

${ }^{* *}$ Correlation is significant at 0.01 level. ${ }^{*}$ Correlation is significant at 0.05 level.

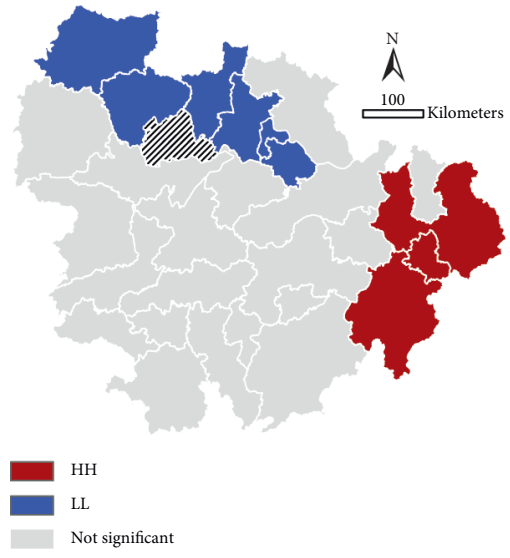

(a)

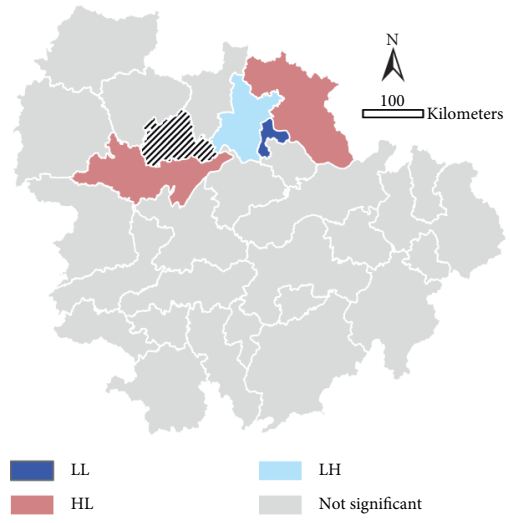

(d)

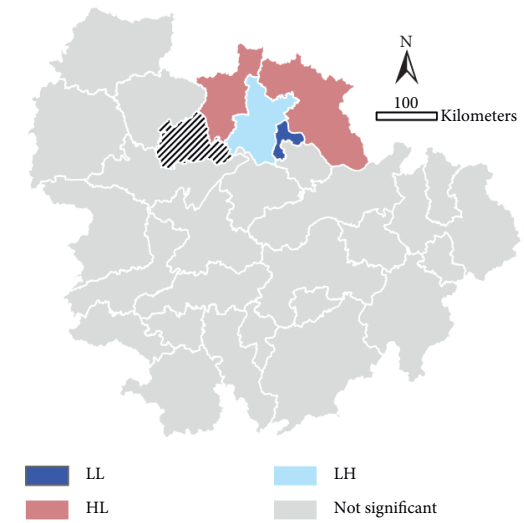

(g)

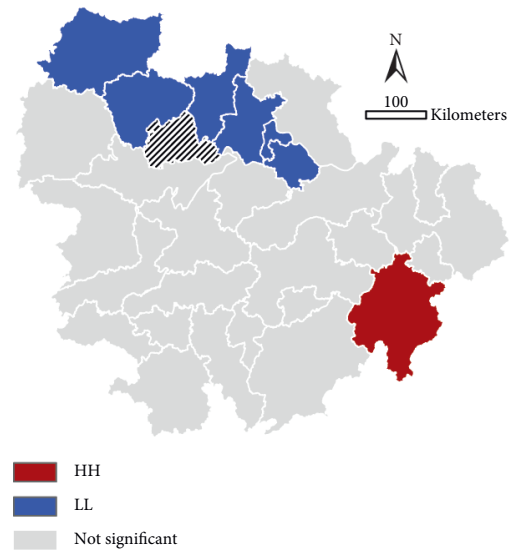

(b)

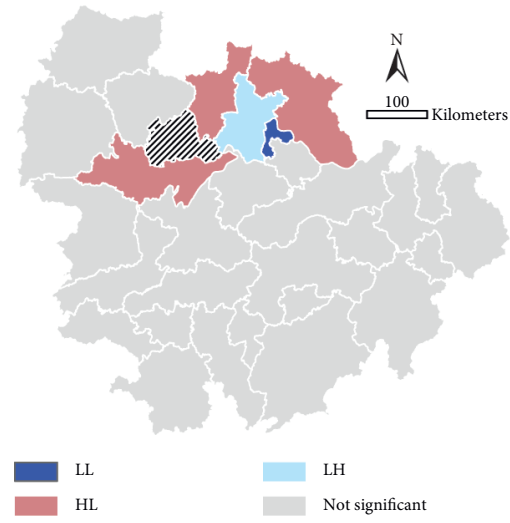

(e)

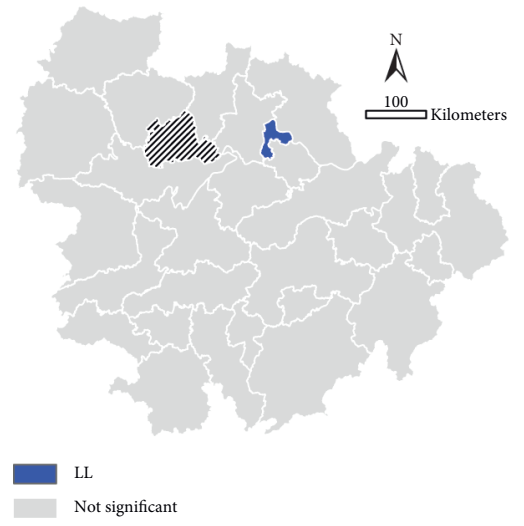

(h)

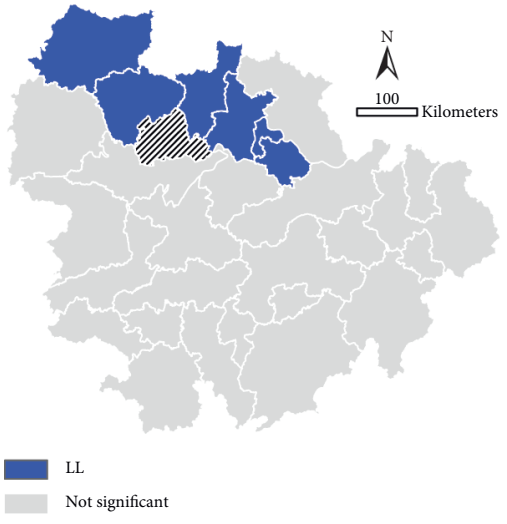

(c)

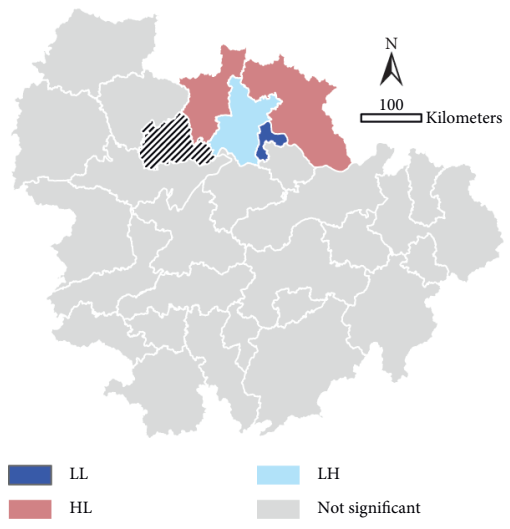

(f)

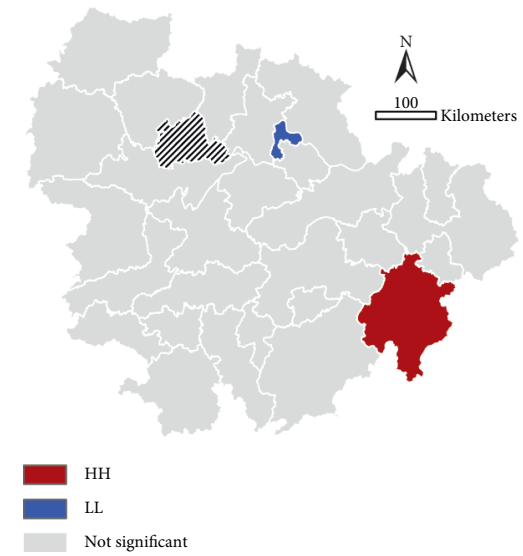

(i)

FIGURE 4: LISA clustering distribution of the in-city travel intensity recovery index by time periods (weeks 1-9): (a) Y3 week 1; (b) Y3 week 2; (c) Y3 week 3; (d) Y4 week 4; (e) Y5 week 5; (f) Y6 week 6; (g) Y7 week 7; (h) Y3 week 8; (i) Y3 week 9. 
TABLE 8: Measurement results of dominant elements of urban resilience (top 10 by $q$ value).

\begin{tabular}{|c|c|c|c|c|c|}
\hline \multicolumn{2}{|l|}{$Y 1$} & \multicolumn{2}{|l|}{$Y 2$} & \multicolumn{2}{|l|}{$Y 3$} \\
\hline Ranking of elements & $q$ & Ranking of elements & $q$ & Ranking of elements & $q$ \\
\hline$E 3$ & $0.687^{* *}$ & $E 2$ & $0.534^{* *}$ & E3 & $0.739^{* * *}$ \\
\hline$S 2$ & $0.527^{* *}$ & E3 & $0.457^{*}$ & $P 3$ & $0.622^{*}$ \\
\hline N5 & $0.461^{*}$ & N5 & $0.403^{*}$ & N4 & $0.613^{* *}$ \\
\hline$E 2$ & 0.382 & $P 4$ & 0.268 & N3 & $0.542^{* *}$ \\
\hline N2 & 0.379 & N2 & 0.257 & $E 4$ & 0.539 \\
\hline$P 4$ & 0.219 & $S 2$ & 0.254 & S6 & 0.534 \\
\hline$N 1$ & 0.173 & $S 4$ & 0.228 & $E 1$ & 0.530 \\
\hline$P 3$ & 0.121 & $S 1$ & 0.205 & $S 4$ & 0.357 \\
\hline$N 4$ & 0.117 & $N 4$ & 0.180 & S3 & 0.345 \\
\hline N6 & 0.106 & $P 1$ & 0.154 & $P 2$ & 0.336 \\
\hline
\end{tabular}

${ }^{* *}$ Correlation is significant at 0.01 level. ${ }^{*}$ Correlation is significant at 0.05 level. Note. The $q$ value not subjected to significance test still has a definite physical significance.

TABLE 9: Results of interaction detection of influential elements of urban resilience (top 10 by $q$ value).

\begin{tabular}{|c|c|c|c|c|c|}
\hline \multicolumn{2}{|l|}{$Y 1$} & \multicolumn{2}{|c|}{$Y 2$} & \multicolumn{2}{|c|}{$Y 3$} \\
\hline Ranking of elements & Interaction $q$ & Ranking of elements & Interaction $q$ & Ranking of elements & Interaction $q$ \\
\hline N5กE3 & 0.975 & $N 1 \cap E 3$ & 0.793 & $P 4 \cap S 2$ & 0.910 \\
\hline$N 6 \cap E 3$ & 0.921 & $E 2 \cap S 2$ & 0.782 & $P 4 \cap N 4$ & 0.888 \\
\hline$P 1 \cap E 3$ & 0.902 & $E 2 \cap S 3$ & 0.777 & $N 4 \cap E 3$ & 0.871 \\
\hline$E 2 \cap S 2$ & 0.888 & $E 2 \cap S 4$ & 0.759 & $N 6 \cap E 3$ & 0.861 \\
\hline$E 3 \cap S 2$ & 0.874 & $E 2 \cap S 1$ & 0.753 & $N 5 \cap E 3$ & 0.851 \\
\hline$P 4 \cap E 3$ & 0.861 & $P 4 \cap N 4$ & 0.742 & $N 1 \cap E 3$ & 0.845 \\
\hline$N 1 \cap E 3$ & 0.856 & $N 4 \cap E 2$ & 0.741 & $P 2 \cap E 3$ & 0.829 \\
\hline$N 4 \cap E 3$ & 0.768 & $E 4 \cap E 2$ & 0.716 & $N 3 \cap E 3$ & 0.811 \\
\hline$N 3 \cap E 3$ & 0.761 & $P 1 \cap E 2$ & 0.715 & $N 2 \cap E 3$ & 0.809 \\
\hline$P 4 \cap S 2$ & 0.754 & $N 3 \cap E 2$ & 0.708 & $P 1 \cap E 3$ & 0.803 \\
\hline
\end{tabular}

interacting with the proportion of tertiary industry. From the viewpoint of the in-city travel intensity recovery index, the explanatory power of the number of schools per 10,000 people $\cap$ the registered unemployment rate in urban areas was the highest (0.910), and the explanatory power of the proportion of tertiary industry, proportion of Internet users, NDVI, population density, and green coverage rate in builtup areas was high when interacting with other elements.

The above-described research revealed that good industrial pattern and employment environment, excellent natural ecology and pollution control, harmonious city scale and form, and complete information infrastructure construction were of utmost significance for the short-term urban socioeconomic recovery. The explanatory power was increased after the interaction of various influential elements, including social, economic, ecological, and engineering subsystems. Among them, the interaction of various elements of the ecological and economic subsystems was more significant, acting together on the dynamic cycle of the urban social ecosystem. Hence, it is essential to enhance the endogenous development momentum of cities by building economic markets and improving space quality.

\subsection{Recommendations on Adaptive Governance Based on Influential Elements}

4.3.1. Ecological and Safe Landscape Pattern Control. Close attention was paid to the significant effects of the economic and ecological subsystems. We further measured the specific landscape metrics to analyze the urban spatial pattern (Figures 5-7). Comparatively, the cities of Jiangxi Province as a whole displayed better ecological connectivity and homogeneity. Hunan Province had fragmented ecological land. Wuhan and its surrounding areas and the cities of Hunan Province revealed a relatively large population and land scale, and relatively concentrated construction land. The SHDI data formed a "double T" high-value distribution pattern with provincial capital cities as nodes in the spatial pattern, with rich landscape patterns and high fragmentation and uncertainty. Coordinating urban construction by integrating existing ecological advantage resources, sorting out urban landscape and construction land structure, enhancing the malleability and connectivity of ecological land, and articulating urban policies combining scale and form are crucial to partially eliminate the pressure on urban scale and density and enhance urban resilience. 


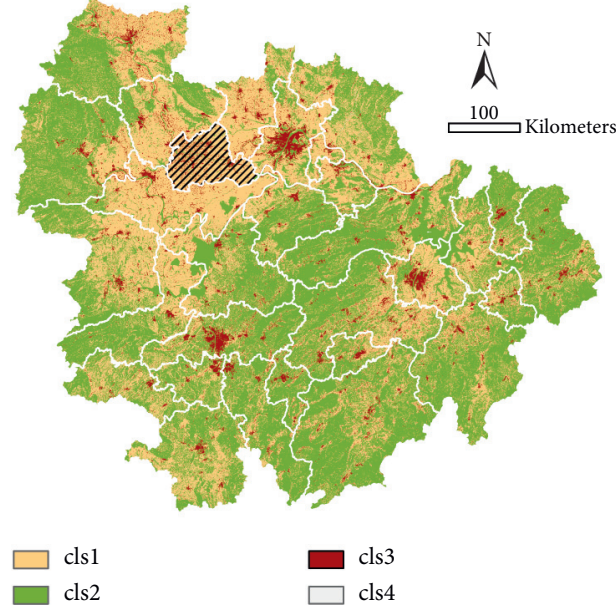

(a)

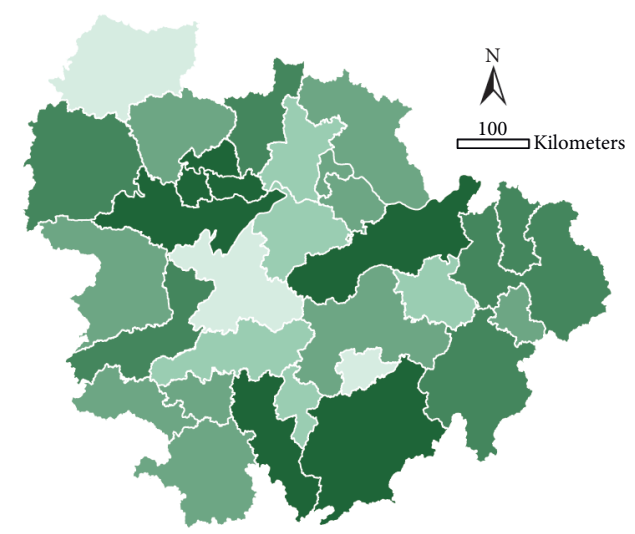

(b)

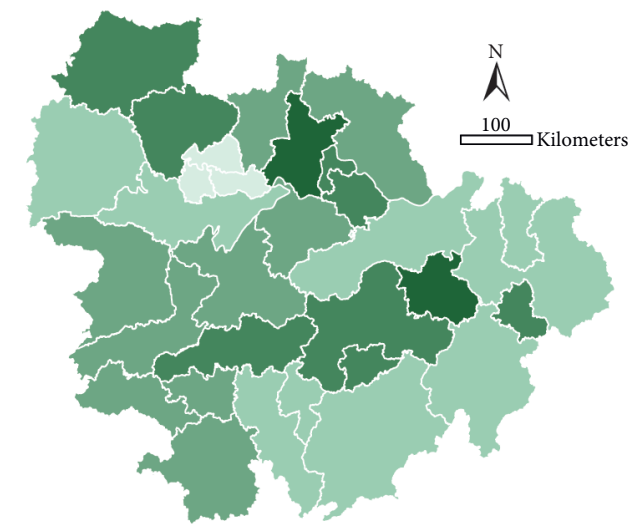

(c)

Figure 5: Spatial distribution of (a) LANDCOVER; (b) CONTAG; (c) SHDI.

\subsubsection{Sustainable Supply Chain Innovation. Figures 8 and 9} show the economic subsystem data and the spatial autocorrelation of the urban innovation and entrepreneurship index and indicate that the Wuhan-Changsha main axis developed vigorously under the connection of the BeijingGuangzhou line in the early years and exhibited the trend of conversion from development along the axis to contiguous distribution. Wuhan City had strong population and economic agglomeration effects; however, its surrounding cities displayed slow economic development and hindered transmission of central functions. Notably, Jiangxi Province exhibited a strong economic situation in recent years, and an innovation economy radiation circle with Nanchang City as the core had been developed. The advantages of each cluster and the economic belt along the river should be connected by constructing transportation and other infrastructure to break down faults and barriers and promote the outward flow of innovative elements in central cities. Furthermore, new ways of ecological priority and green development should be actively investigated to build an area regional economic development community with complementary advantages.
4.3.3. Multiple Efforts, Adaptation to Local Conditions, and Interval Coordination. Adaptive governance measures should be actively investigated to respond to uncertain disturbances similar to pandemic events to enhance the risk adaptability and sustainable development capability of cities. Besides, measures like multiple efforts, adaptation to local conditions, and interval coordination should be considered to upgrade the system cycle mechanism. Based on the local spatial autocorrelation of eight dominant elements in Figure 10 and the spatial distribution of 20 indicators, it can be inferred that the three provincial capital cities had unique location advantages and policy advantages; however, more space was available to develop the radiation and driving effect of economy and informatization. Comparatively, Jiangxi Province had significant advantages in the environmental resilience subsystem, while Wuhan City and Ezhou City had great pressure on the urban human settlement environment and low vegetation index and green coverage in built-up areas. The northern cities in the middle reaches of the Yangtze River were relatively weak in withstanding and adaptation to risks at the economic level. It was a must to focus on the 


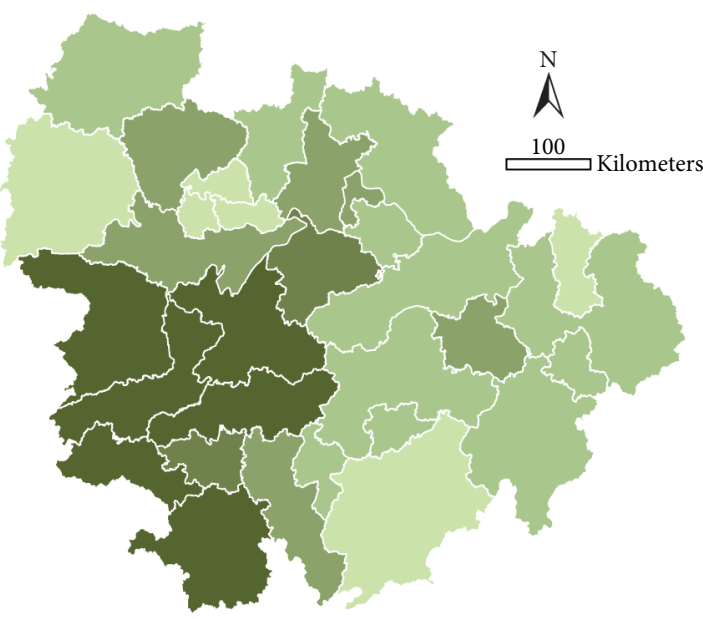

(a)

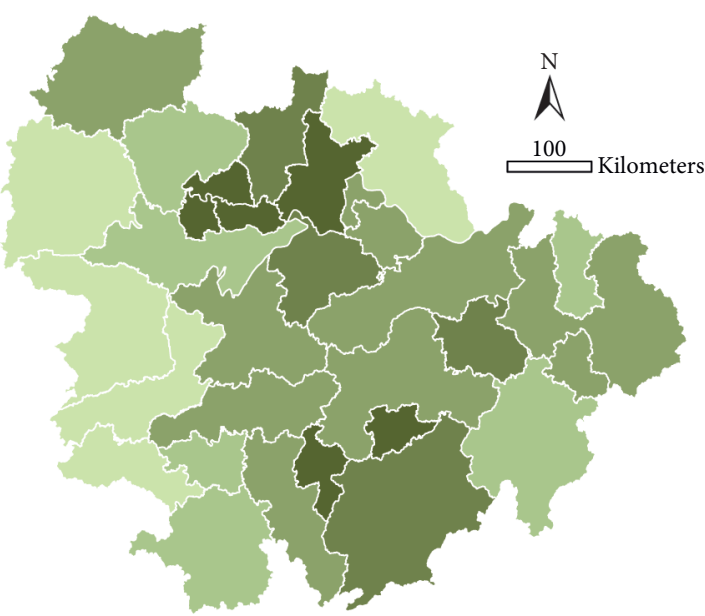

(c)

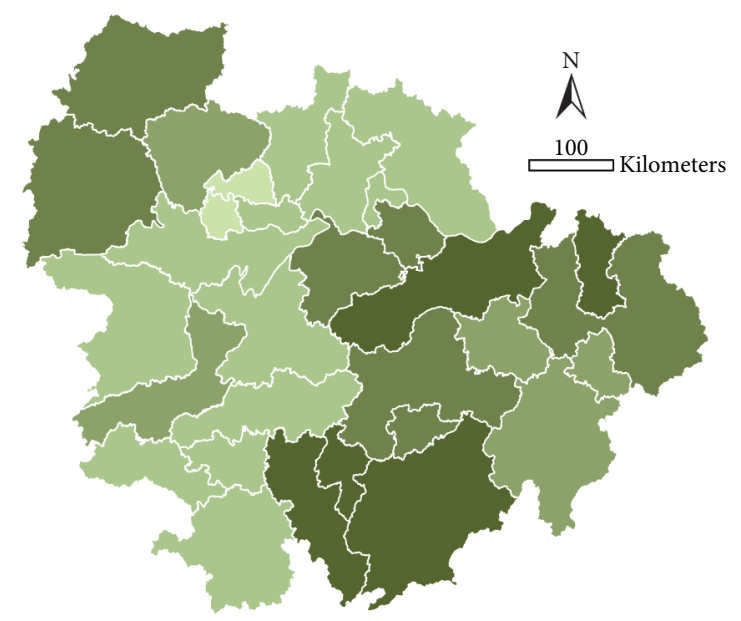

(b)

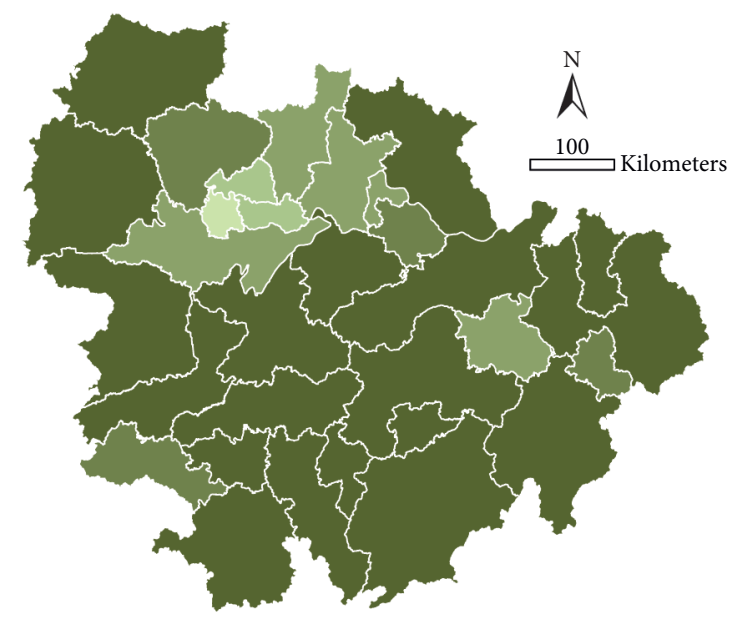

(d)

FIGURE 6: Landscape metrics of ecological land: (a) cls 2-PD; (b) cls 2-AL; (c) cls 2-IJI; (d) cls 2-COHESION.

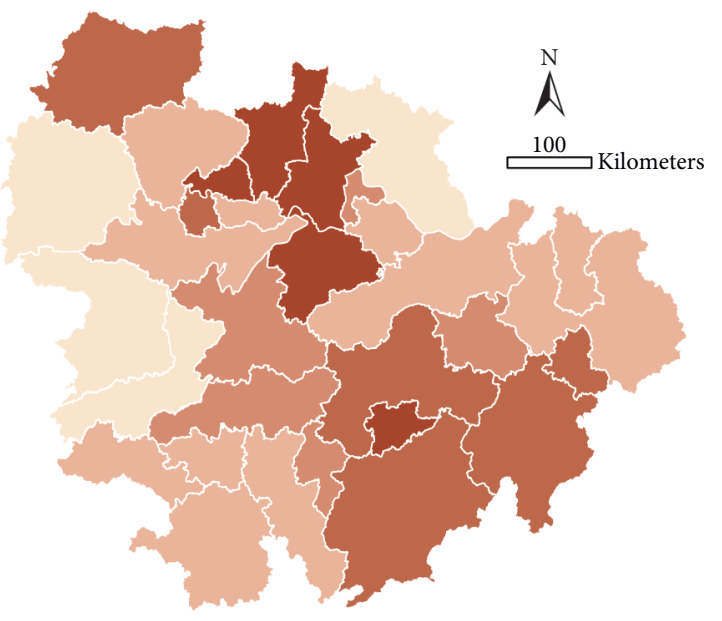

(a)

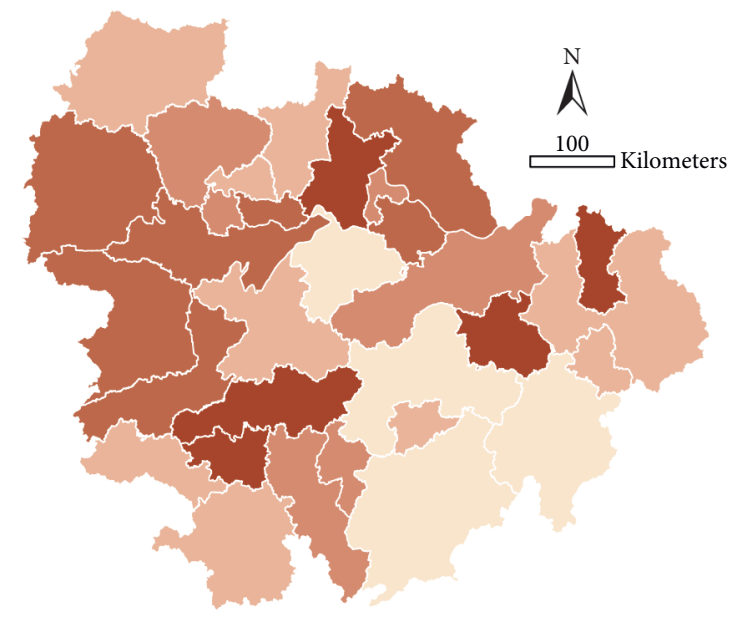

(b)

Figure 7: Continued. 


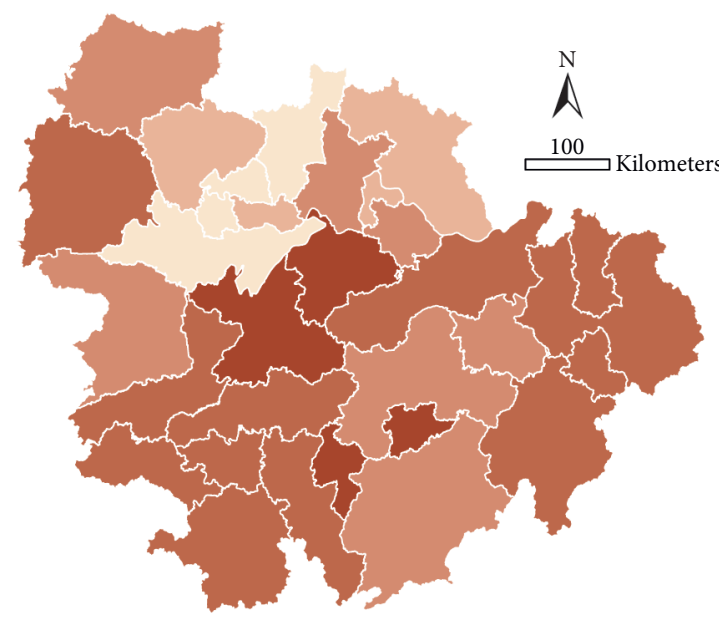

(c)

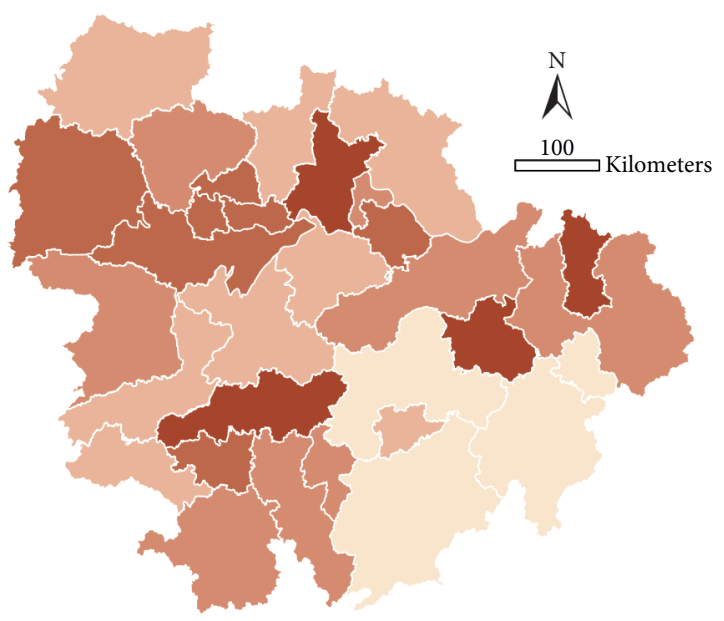

(d)

FIgURE 7: Landscape metrics of construction land: (a) cls 3-PD; (b) cls 3-AL; (c) cls 3-IJI; (d) cls 3-COHESION.

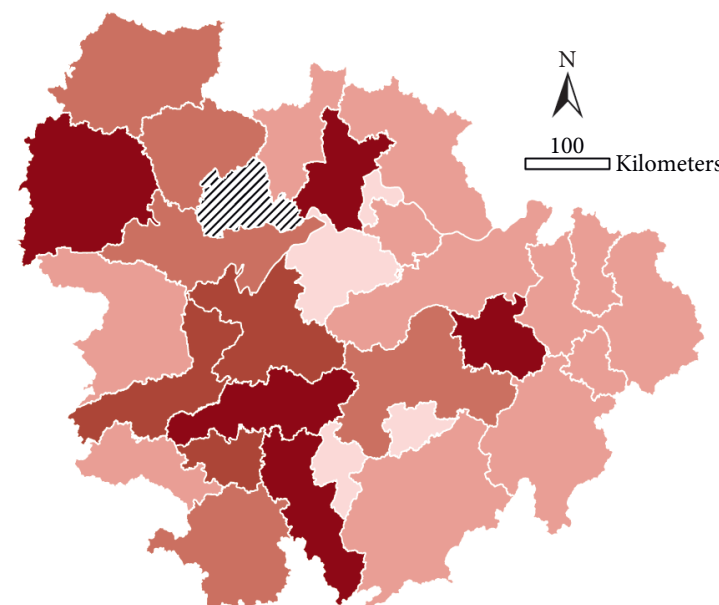

(a)

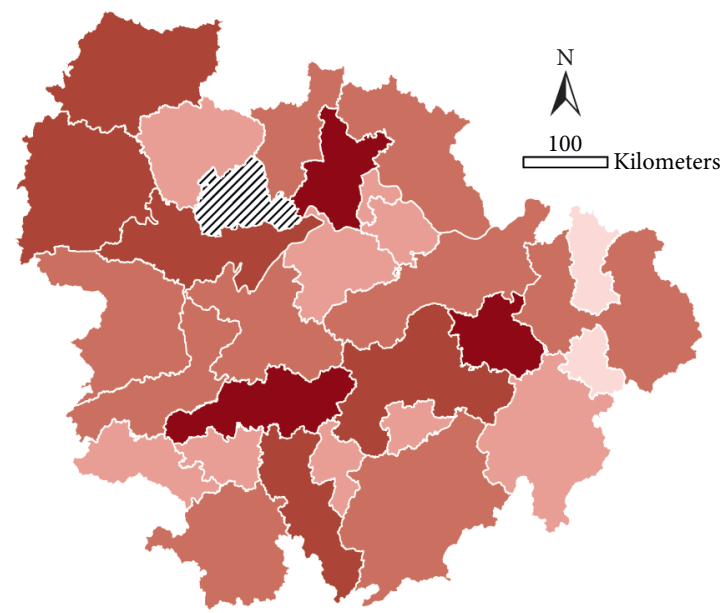

(c)

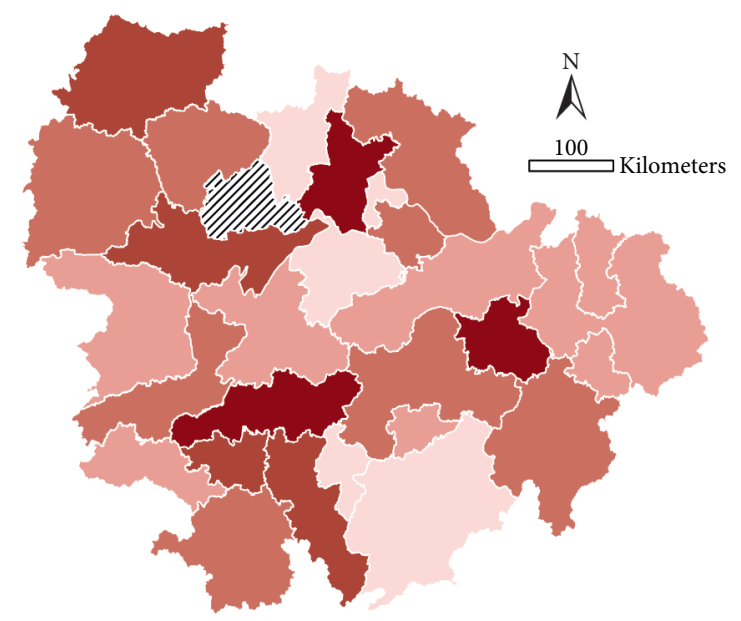

(b)

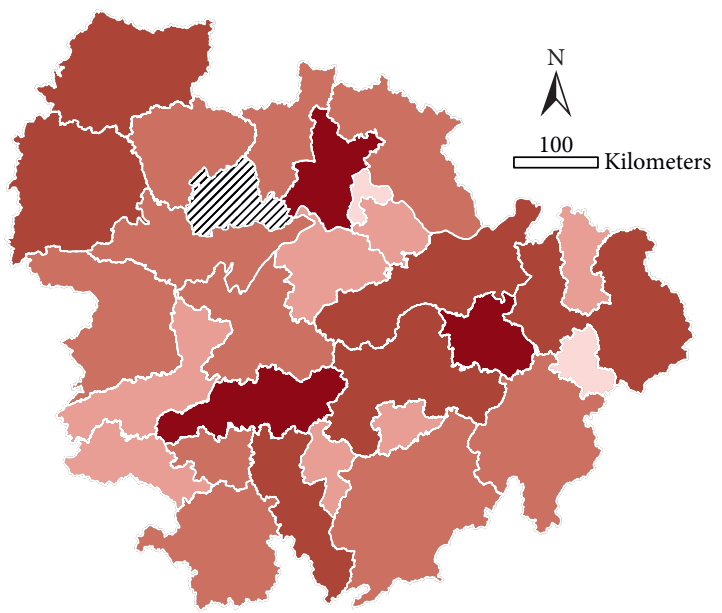

(d)

FIGURE 8: Spatial distribution of urban innovation and entrepreneurship index in (a) 2002, (b) 2007, (c) 2012 , and (d) 2017. 


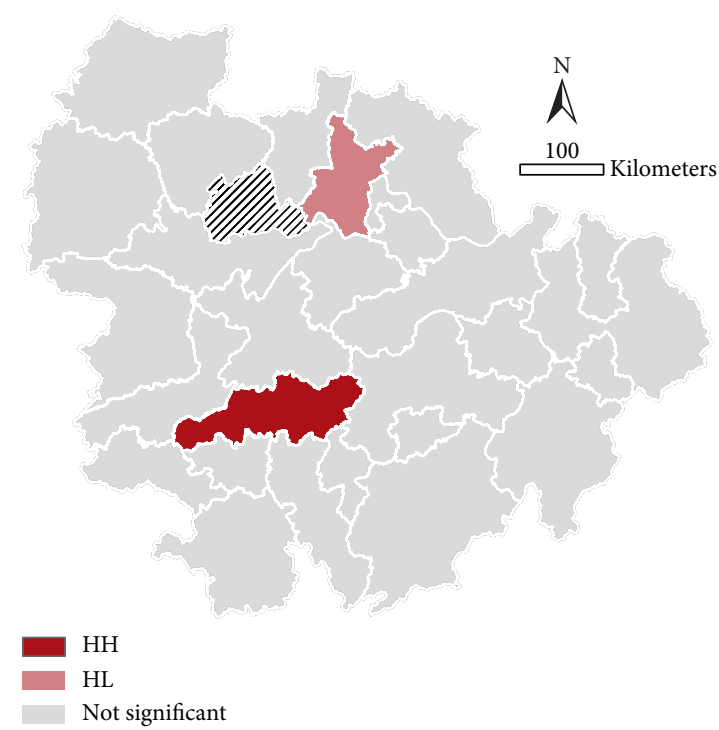

(a)

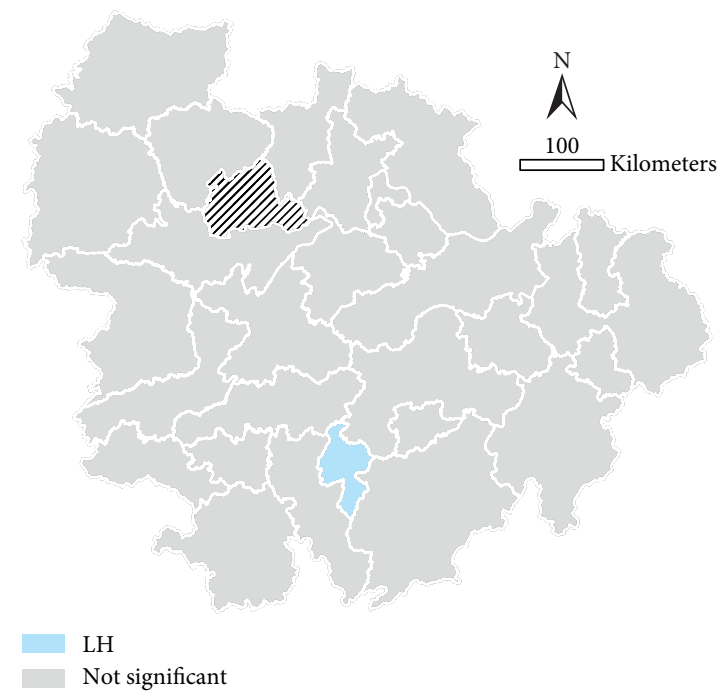

(c)

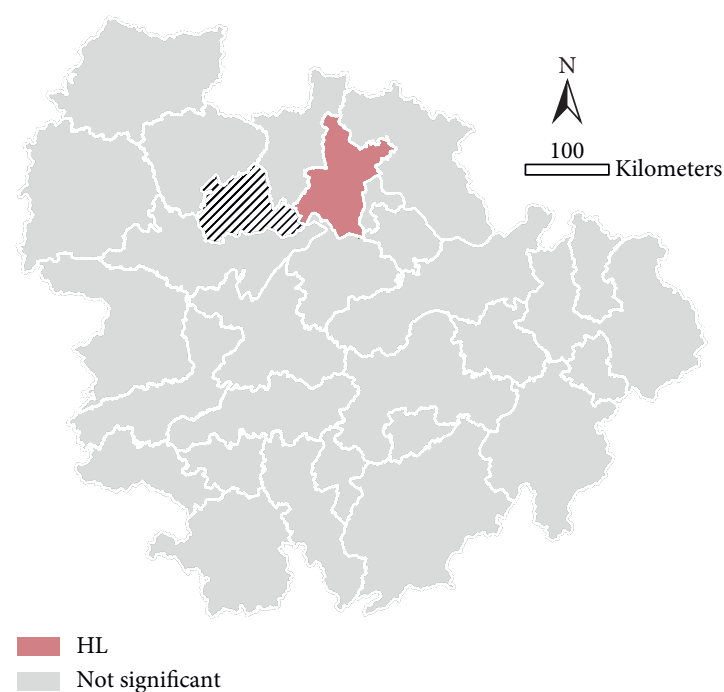

(b)

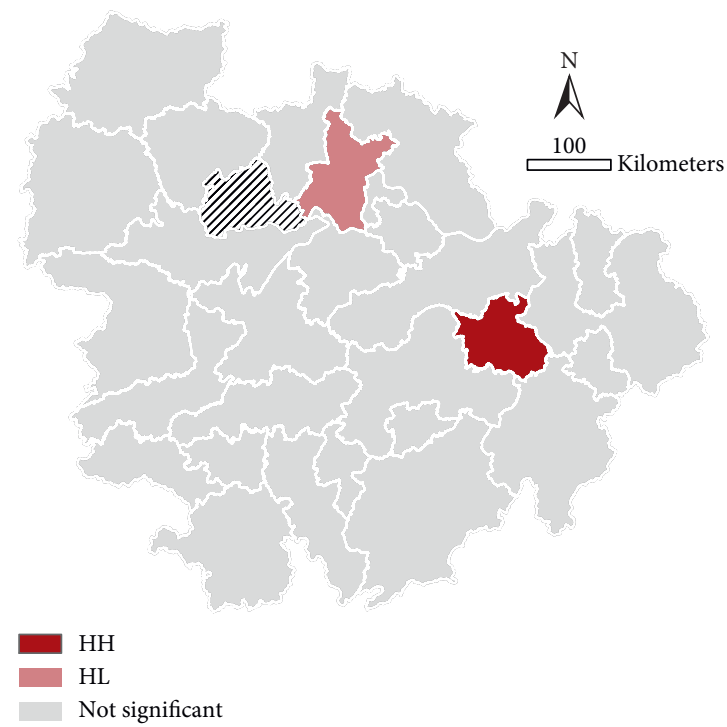

(d)

FIGURE 9: LISA clustering distribution of urban innovation and entrepreneurship index in (a) 2002, (b) 2007, (c) 2012, and (d) 2017.

economic growth momentum and the degree of advanced industrial structure of cities. Overall, there remains scope for improvement in economic innovation and green development in Hubei Province; thus, the absorption capacity of Wuhan's surrounding cities to receive spillovers from central cities must be strengthened. Jiangxi Province had significant advantages in resource utilization and sustainable environmental development; therefore, attention must be paid to the efficiency of economic output and the cultivation of high-quality talents. Hunan Province had good economic, scientific, and educational development trends; however, issues like balanced economic development and environmental governance must be settled urgently to avoid extensive and inefficient use of resources and excessive concentration of chemical industry. It is imperative to further play the economic radiation role of central cities and augment the absorption capacity of smalland medium-sized cities to create the multicenter development pattern with Wuhan, Changsha, and Nanchang as centers and Ezhou, Zhuzhou, and Jiujiang as regional subcenters. Besides, it is crucial to further explore the advantageous and characteristic industries of subgroups of 

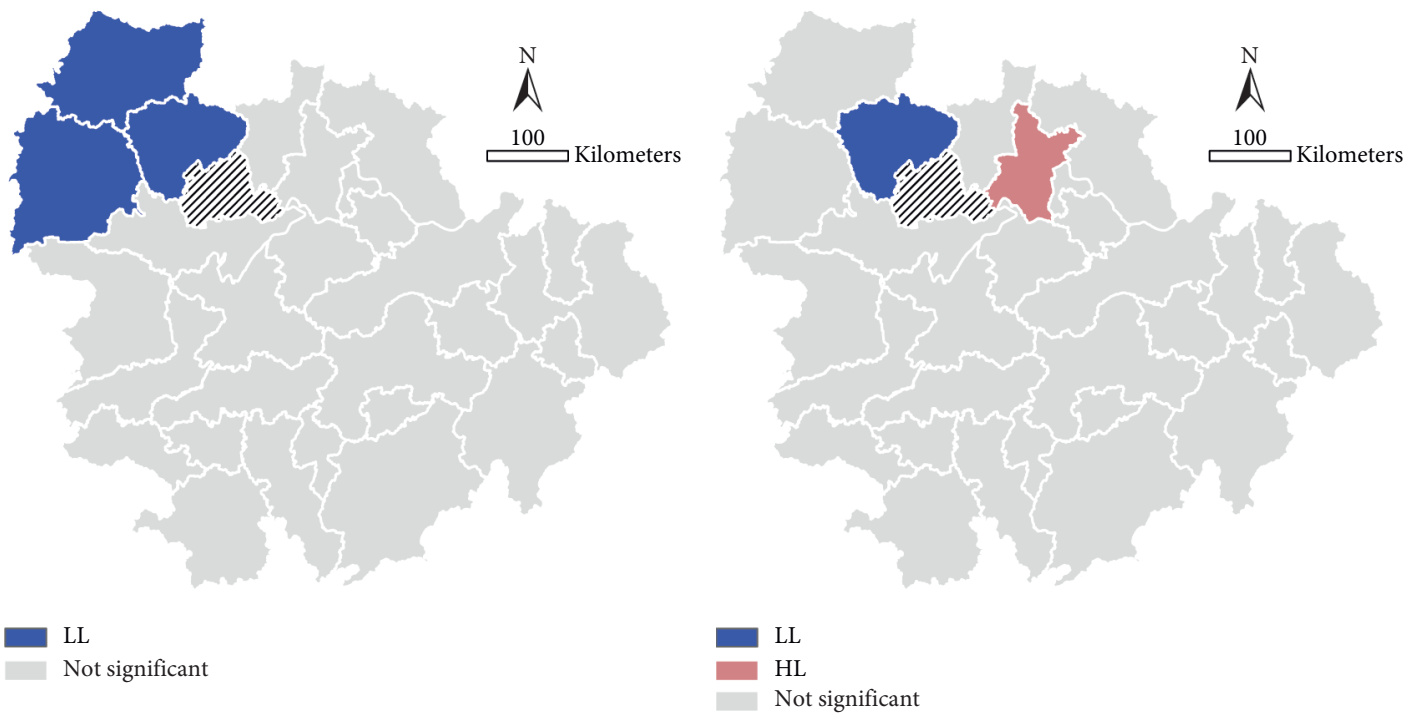

(a)

(b)
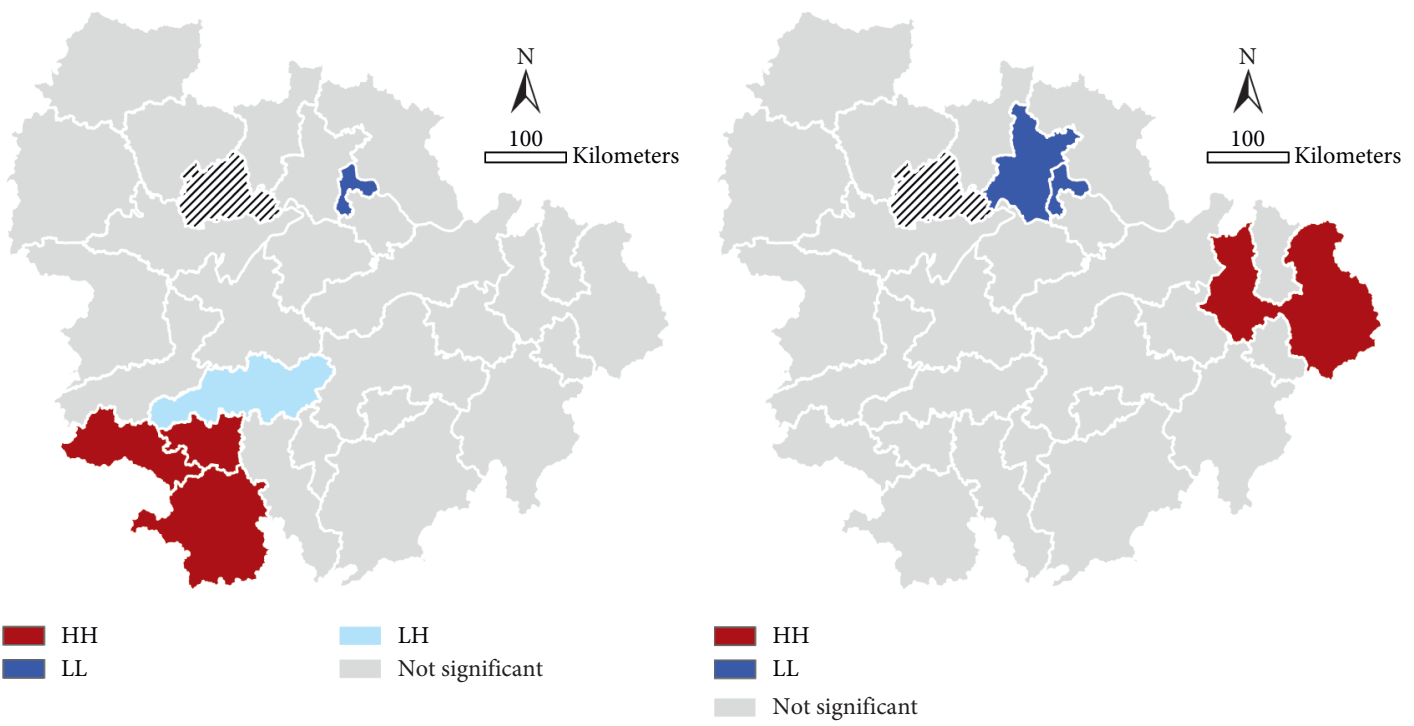

$\mathrm{HH}$
$\mathrm{LL}$

LH
Not significant

(d)
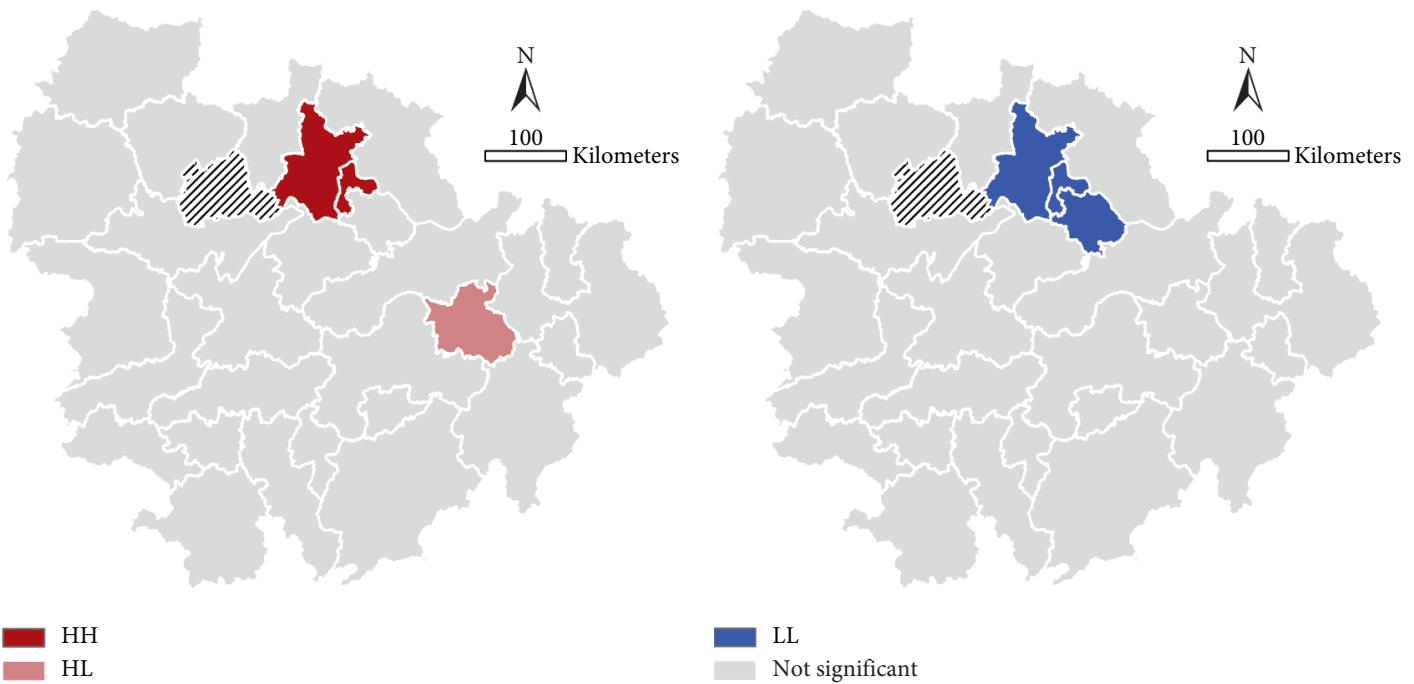

단

Not significant

(e)

(f)

Figure 10: Continued. 


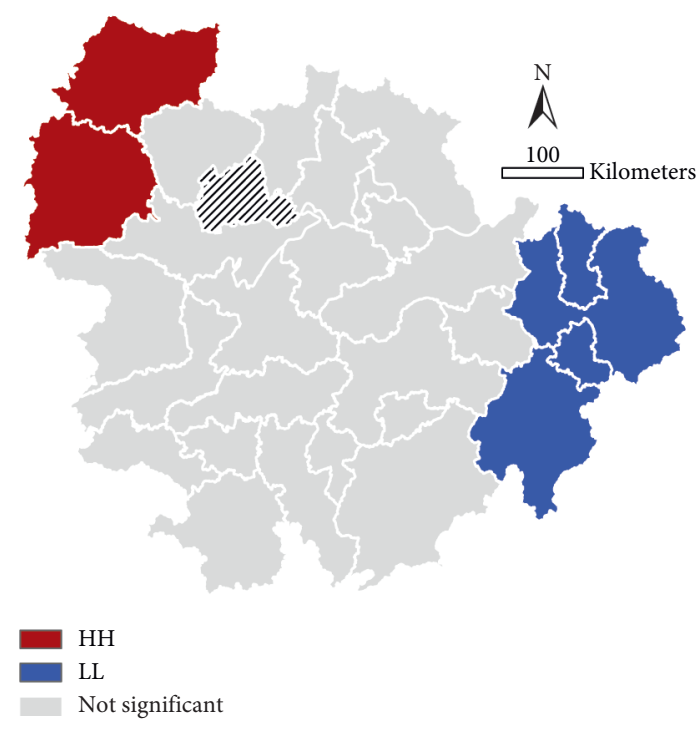

(g)

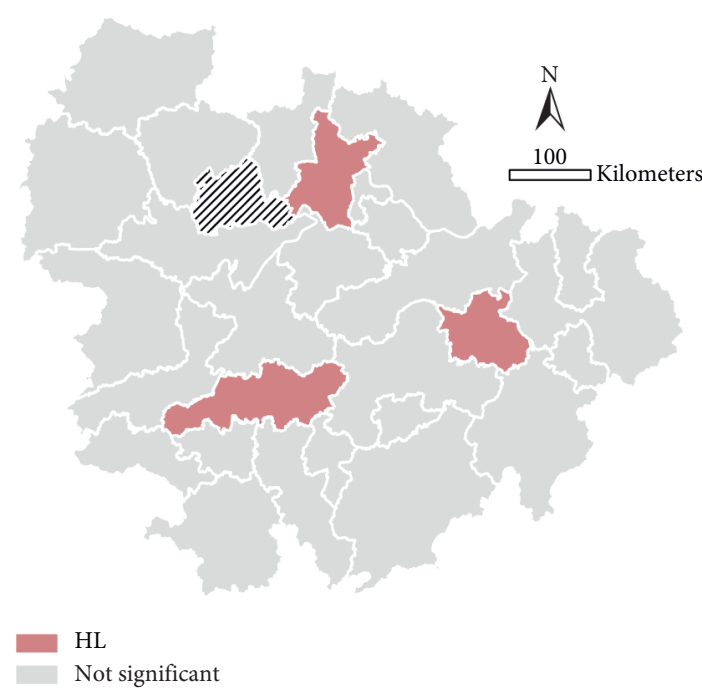

(h)

Figure 10: LISA clustering distribution of dominant elements of urban resilience: (a) E2; (b) E3; (c) S2; (d) N2; (e) N3; (f) N4; (g) N5; (h) P3.

each city and dynamically promote industry convergence and cooperation to promote the clustering of advantageous industries.

\section{Conclusions}

In the event of the pandemic, urban resilience in the middle reaches of the Yangtze River showed significant characteristics of spatial agglomeration, with a roughly spatial trend of decreasing from south to north. The cities along the southeast wing had a good recovery trend in the year-onyear growth rate of total electricity consumption and in-city travel intensity recovery index. The overall economic recovery and development of the cities of Hunan Province were relatively balanced.

The spatial differentiation of urban resilience in the middle reaches of the Yangtze River is a comprehensive outcome of the interaction of various elements. The independent and interactive forces of ecological and economic subsystems are significant. The proportion of the tertiary industry, GDP growth rate, registered unemployment rate in urban areas, AQI, NDVI, green coverage rate in built-up areas, population density, and proportion of Internet users play key roles in short-term social and economic recovery of cities.

Currently, attaining the transformation and upgrading of traditional industries by increasing the ability of cities around the provincial capital to receive spillover resource, optimizing the spatial pattern of ecological land and construction land in Hunan and Hubei Provinces, and promoting the overall sustainable supply chain innovation in the region constitute the major breakthrough promoting the resilience and sustainable development of the region.

In this study, the level of urban resilience in the research areas was jointly characterized by three elements (GDP year-onyear growth rate, year-on-year growth rate of total electricity consumption, and in-city travel intensity recovery index), which have different characteristics and limitations, and a more scientific description of urban resilience warrants further investigation. The selection of elements has a clearer event orientation and geographical orientation, and its external validity also warrants verification. The socioeconomic recovery status of each city under the pandemic closely correlated with administrative power, which was not extensively discussed in this study owing to the limited length of the research. The urban SES is a dynamic structure under the interaction of multiple subjects and elements, which is challenging to analyze. Bias is inevitable in the process of scientific argumentation in this study. The ability to comprehend the urban system should be improved in future research and practice, and dynamic governance strategies should be adopted, which is of utmost significance for the construction of a resilient and sustainable urban development spatial coordination mechanism.

\section{Data Availability}

The data source is specifically described in Section 3.3, and the data used to support the findings of this study are included within the article.

\section{Additional Points}

(1) Only some counties (districts) in Fuzhou City and Ji'an City are included in the urban agglomeration in the middle reaches of the Yangtze River, but the entire cities of Ji'an and Fuzhou are included in this study to facilitate data acquisition and maintain the integrity of the research areas. (2) The Statistical Yearbook 2018 used in this study publishes statistical data of 2017.

\section{Conflicts of Interest}

The authors declare that they have no conflicts of interest. 


\section{Acknowledgments}

This project was supported by the National Natural Science Foundation of China (Grant no. 51778400). The authors would like to thank the Development and Reform Commission of Hunan Province, State Grid Hunan Electric Power Company Limited, Huangshi City Government, Hengyang City Government, Yiyang City Government, Xiangtan City Government, Changsha City Government, Energy Division, Hunan Provincial Bureau of Statistics, Tianmen City Government, Xiantao City Government, and Qianjiang City Government for providing government data assistance during the writing of the study.

\section{References}

[1] N. Zhu, D. Zhang, W. Wang et al., "A novel coronavirus from patients with pneumonia in China, 2019," New England Journal of Medicine, vol. 382, no. 8, 2020.

[2] WHO, Novel Coronavirus (2019-nCoV) Situation Report -11, World Health Organization, Geneva, Switzerland, 2020.

[3] J. Ma and H. Ren, "Influence of government regulation on the stability of dual-channel recycling model based on customer expectation," Nonlinear Dynamics, vol. 94, no. 3, pp. 1775-1790, 2018.

[4] G. Olcott and N. Oliver, "Social capital, sensemaking, and recovery: japanese companies and the 2011 earthquake," California Management Review, vol. 56, no. 2, 2014.

[5] L. Wang and J. Zhao, "Spatiotemporal distribution pattern of the COVID- 19 epidemic and geographical detection," Acta Ecologica Sinica, vol. 40, no. 19, pp. 6788-6800, 2020.

[6] Q. Ma, C. Kan, Y. Gong, and A. Dang, "Recovery of urban vitality and its influencing factors:exploration based on the scenario of the outbreak of public health emergencies," City Planning Review, vol. 44, no. 9, pp. 22-27, 2020.

[7] W. Li, S. Zhao, X. Ji, and J. Ma, "Impact of traffic exposure and land use patterns on the risk of COVID-19 spread at the community level," China Journal of Highway and Transport, vol. 33, no. 11, pp. 43-54, 2020.

[8] Y.-J. Yang, C.-C. Chen, Y.-T. Chen, and L. Pei, "New method of solving the economic complex systems," Discrete Dynamics in Nature and Society, vol. 2020, Article ID 8827544, 26 pages, 2020.

[9] R. J. T. Klein, R. J. Nicholls, and F. Thomalla, "Resilience to natural hazards: how useful is this concept?" Global Environmental Change B: Environmental Hazards, vol. 5, no. 1, 2004.

[10] M. Lennon, M. Scott, M. Collier, and K. Foley, "The emergence of green infrastructure as promoting the centralisation of a landscape perspective in spatial planning-the case of Ireland," Landscape Research, vol. 42, no. 2, 2017.

[11] B. C. Chaffin, H. Gosnell, and B. A. Cosens, "A decade of adaptive governance scholarship: synthesis and future directions," Ecology and Society, vol. 19, no. 3, 2014.

[12] J. Ma, Y. Cui, and Liulixia, "A study on the complexity of a business cycle model with great excitements in non-resonant condition," Chaos, Solitons \& Fractals, vol. 39, no. 5, pp. 2258-2267, 2009.

[13] M. Junhai, S. Lijian, H. Shunqi, and Z. Xueli, "Complexity study on the Cournot-Bertrand mixed duopoly game model with market share preference," Chaos (Woodbury, N.Y.), vol. 28, no. 2, 2018.
[14] F. Wu and J. Ma, "The equilibrium, complexity analysis and control in epiphytic supply chain with product horizontal diversification," Nonlinear Dynamics, vol. 93, no. 4, 2018.

[15] J. Ma and L. Xie, "The stability analysis of the dynamic pricing strategy for bundling goods: a comparison between simultaneous and sequential pricing mechanism," Nonlinear Dynamics, vol. 95, no. 2, 2019.

[16] J. Ma and L. Sun, "Complexity analysis about nonlinear mixed oligopolies game based on production cooperation," IEEE Transactions on Control Systems Technology, vol. 26, no. 4, pp. 1532-1539, 2020.

[17] J. Ma and L. Xie, "The comparison and complex analysis on dual-channel supply chain under different channel power structures and uncertain demand," Nonlinear Dynamics, vol. 83, no. 3, pp. 1379-1393, 2016.

[18] B. Bao, J. Ma, and M. Goh, "Short- and long-term repeated game behaviours of two parallel supply chains based on government subsidy in the vehicle market," International Journal of Production Research, vol. 58, no. 24, pp. 7507-7530, 2020.

[19] C. Fox-Lent, M. E. Bates, and I. Linkov, "A matrix approach to community resilience assessment: an illustrative case at Rockaway Peninsula," Environment Systems and Decisions, vol. 35, no. 2, 2015.

[20] P. M. Orencio and M. Fujii, “A localized disaster-resilience index to assess coastal communities based on an analytic hierarchy process (AHP)," International Journal of Disaster Risk Reduction, vol. 3, 2013.

[21] M. Nyström, J. B. Jouffray, A. V. Norström et al., "Anatomy and resilience of the global production ecosystem," Nature, vol. 5757781 pages, 2019.

[22] D. A. O'Connell, B. Walker, and N. Abel, The Resilience, Adaptation and Transformation Assessment Framework: From Theory to Application, CSIRO, " Canberra,Australia, 2015.

[23] S. L. Cutter, D. A. Kevin, and T. E. Christopher, "The geographies of community disaster resilience," Global Environmental Change, vol. 29, 2014.

[24] W. Katharine, D. Darrin, and L. Nicole, "What is health resilience and how can we build it?" Annual Review of Public Health, vol. 36, 2015.

[25] C. Folke, "Resilience: the emergence of a perspective for social-ecological systems analyses," Global Environmental Change, vol. 16, no. 3, 2006.

[26] L. Geng, R. Xiao, X. Xu, and W. Liu, "Research on MAS-based supply chain resilience and its self-organized criticality," Discrete Dynamics in Nature and Society, vol. 2014, Article ID 621341, , 2014.

[27] J. H. Holland, "Studying complex adaptive systems," Journal of Systems Science and Complexity, vol. 19, no. 1, pp. 1-8, 2006.

[28] R. Martin, P. Sunley, B. Gardiner, and P. Tyler, "How regions react to recessions: resilience and the role of economic structure," Regional Studies, vol. 50, no. 4, 2016.

[29] Y. Yang, S. Zhan, Q. Jiang, and C. Fu, "Spatiotemporal characteristics of coronavirus disease 2019 in 258 cities in China," Disease Surveillance, vol. 35, no. 11, pp. 977-981, 2020.

[30] Y. Song, M. Liu, W. Jia et al., "Epidemic characteristics and trend analysis of COVID-19 in Hubei province," Chinese Journal of Epidemiology, vol. 41, no. 09, pp. 1396-1400, 2020.

[31] A. Getis, A. D. "Cliff, and J. K. Ord, "Spatial autocorrelation. London: pion," Progress in Human Geography, vol. 19, no. 2, 1995.

[32] J. Wang and C. Xu, "geodetector: principle and prospective," Acta Geographica Sinica, vol. 72, no. 1, pp. 116-134, 2017. 